\title{
WHAT'S STEERING CONSUMER PREFERENCES FOR AUTONOMOUS VEHICLES IN THE GREATER TORONTO AND HAMILTON AREA?
}

by

\author{
Kailey Laidlaw \\ B.A, University of Victoria, 2015
}

A Major Research Paper presented to Ryerson University in partial fulfillment of the requirements for the degree of Master of Planning in Urban Development

Toronto, Ontario, Canada, 2017

OKailey Laidlaw, 2017 


\section{AUTHOR'S DECLARATION FOR ELECTRONIC SUBMISSION OF A MRP}

I hereby declare that I am the sole author of this MRP. This is a true copy of the MRP, including any required final revisions.

I authorize Ryerson University to lend this MRP to other institutions or individuals for the purpose of scholarly research I further authorize Ryerson University to reproduce this MRP by photocopying or by other means, in total or in part, at the request of other institutions or individuals for the purpose of scholarly research.

I understand that my MRP may be made electronically available to the public. 


\title{
WHAT'S STEERING CONSUMER PREFERENCES FOR AUTONOMOUS VEHICLES IN THE GREATER TORONTO AND HAMILTON AREA
}

\author{
CKailey Laidlaw, 2017. \\ Master of Planning in Urban Development \\ Ryerson University \\ ABSTRACT
}

Automated vehicles (AVs) have the potential to change the way we travel within our cities.

However, the conditions under which consumers will adopt AVs are poorly understood. An internet-based survey was conducted in the Greater Toronto and Hamilton Area to understand how consumers will respond to automated vehicles. This study estimates the effect of demographic characteristics, travel characteristics, and built-environment variables on respondent's willingness to pay for private autonomous vehicles and frequency of use for shared autonomous vehicles under different pricing levels. The results indicate that having a higher household income and owning a more expensive vehicle are good predictors of interest in PAVs, whereas individuals who experienced more car accidents as a passenger and individuals who commute using public transit or walk/cycle are more interested in SAVs. Regional rail users, Uber users, and younger respondents were interested in both ownership models. This provides insight to help policymakers advance transportation policies and collective social goals.

Keywords: Autonomous Vehicles; Private Autonomous Vehicles; Shared Autonomous Vehicles; Survey; Consumer Preferences; Transportation Planning. 


\section{Acknowledgements}

This project was made possible by many incredibly inspiring individuals. The energy, patience, and dedication of Dr. Matthias Sweet helped craft and refine this paper. Thank you for the meaningful discussions and guidance.

Thank you to my family and fellow colleagues at Ryerson University and the Transform Lab for the motivation, laughs, and thought-provoking conversations. I am grateful for the supportive community at Ryerson that has allowed me to challenge myself.

My love and appreciation always for Robert, thank you for encouraging me throughout this academic journey.

My appreciation also extends to Dr. Raktim Mitra for his insights and contributions. 


\section{Table of Contents}

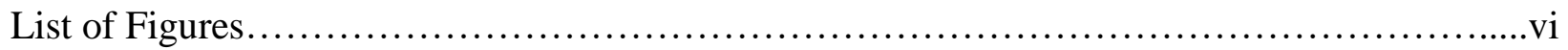

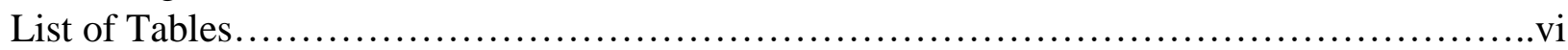

Chapter 1: Introduction .................................................................................................. 1

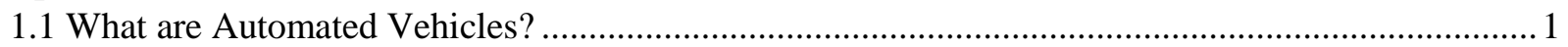

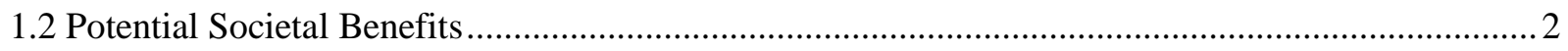

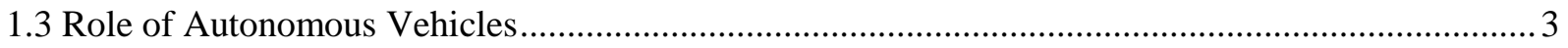

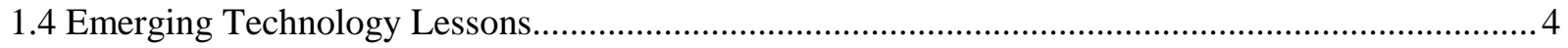

Chapter 2: Existing Literature ............................................................................................ 5

2.1 The Potential Benefits, Costs, and Impacts ………………………………………................

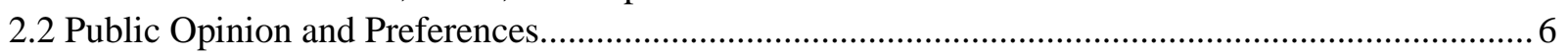

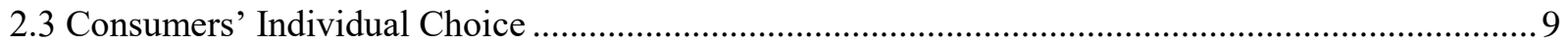

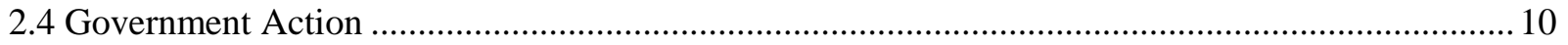

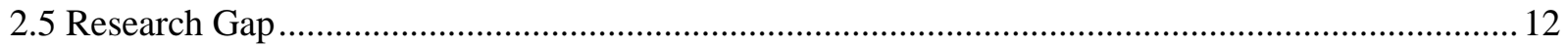

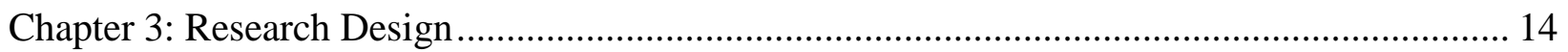

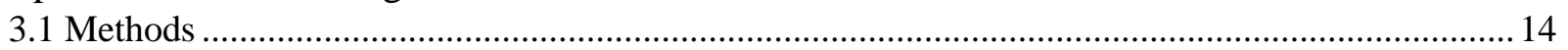

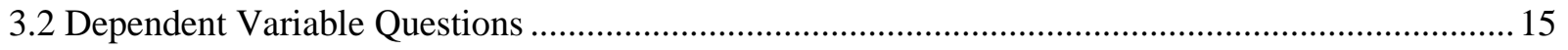

3.3 Modelling Estimation ……………………………………………………………………. 15

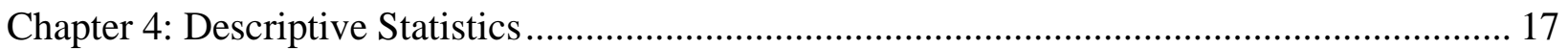

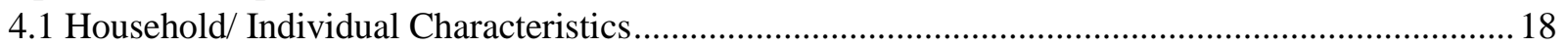

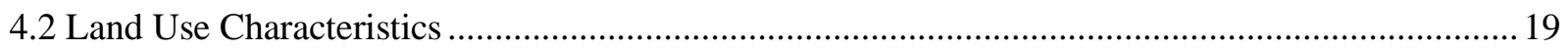

4.3 Commuting/Travel Behaviour ......................................................................................... 19

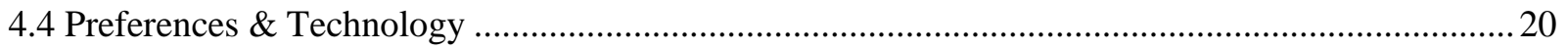

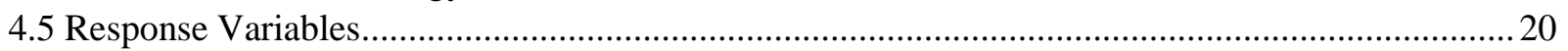

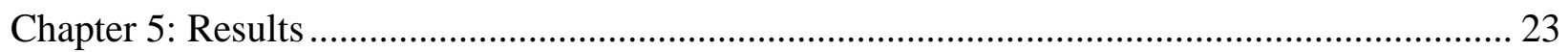

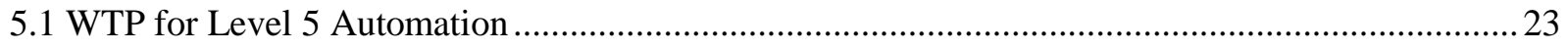

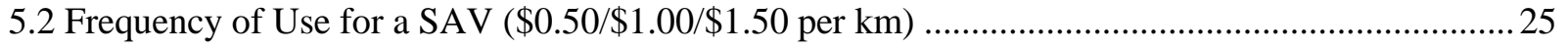

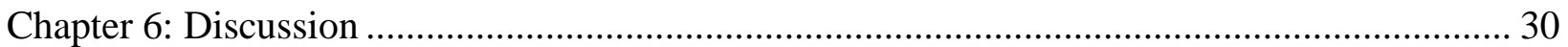

6.1 Private vs. Shared Autonomous Vehicles...................................................................................... 30

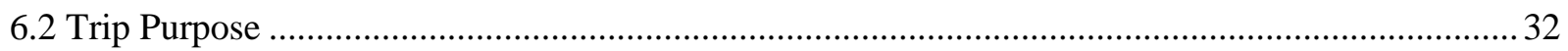

6.3 Implications of Research .................................................................................................... 33

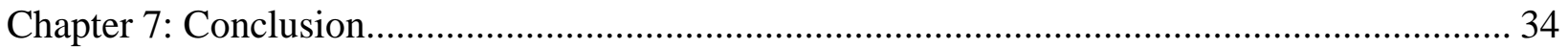

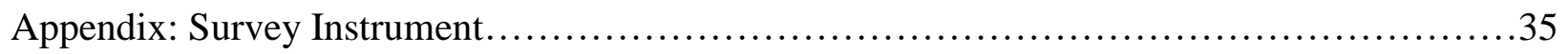

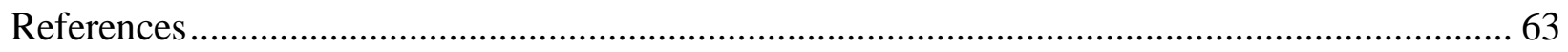




\section{List of Figures}

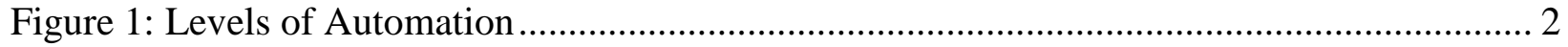

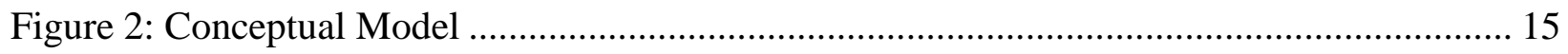

\section{List of Tables}

Table 1: Frequency Counts of Explanatory Variables. 17

Table 2: Population-weighted Results for Response Variables ............................................. 21

Table 3: Willingness to Pay for Level 5 Automation ............................................................ 24

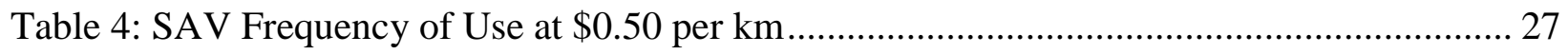

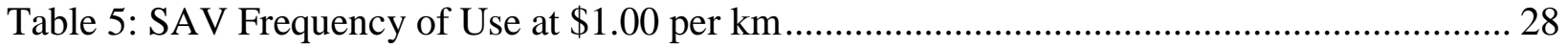

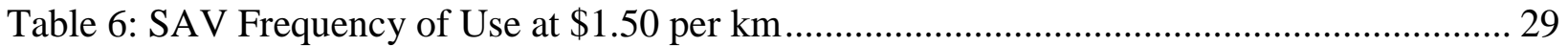

Table 7: WTP for Level 5 and Frequency of using SAVs at $\$ 0.50$ per km .............................. 30 


\section{Chapter 1: Introduction}

Autonomous or self-driving vehicles are no longer confined to the realm of science fiction; the technology is quickly approaching the point at which it will be made available to the public. Industry experts predict that fully autonomous vehicles will penetrate the consumer market within the next fifteen years (Litman, 2017). Corporations such as Google, Uber, Tesla, Toyota, and General Motors have heavily invested in autonomous vehicle technology (Muoio, 2016); many of these companies are already testing their autonomous vehicles on city roads around the world. While private-sector technology companies are investigating and investing in advances in vehicular technology, the broader implications of this technology on society, cities, and the environment is poorly understood - leading to little clarity in public policy design for shaping this privately-produced technology for a collective good. Perhaps most importantly, there is little understanding of the social and economic conditions under which different users may adopt this technology.

\subsection{What are Automated Vehicles?}

Automated Vehicles (AVs) cannot be categorized as one type of vehicle. Rather, automated vehicles vary in how many automated features they have to replace or complement the human driver. The level of automation in a vehicle is typically ranked using a five-point scale that ranges from no automation (level 0) to fully autonomous (level 5) as shown in (Society of Automative Engineers, 2014). The level of automation is a reflection of the technology that will be employed in these vehicles. Autonomous vehicles use a combination of sensors, Light Detection and Ranging (LIDAR), and radar, to perform the functions of driving. Communications between AVs and infrastructure (V2I) and AVs and other connected vehicles (V2V) operate through dedicated short range communications (DRSC) or lite range cellular (LITE).

The private sector's version of automated capabilities certainly will not fit neatly into any of the five categories. Many new vehicles on the market today have level 2 capabilities or advanced driver assistance systems (ADAS); this includes features such as lane assist, cruise control, and 
automatic breaking. The most widely discussed example of a fully autonomous vehicle (level 5) is the Google Car; the company's prototype vehicles have accumulated over 2 million miles on city streets ever since testing began in 2009 (Google, 2016).

Figure 1: Levels of Automation

\begin{tabular}{|c|c|c|c|c|c|c|}
\hline $\begin{array}{l}\text { SAE } \\
\text { level }\end{array}$ & Name & Narrative Definition & $\begin{array}{l}\text { Execution of } \\
\text { Steering and } \\
\text { Acceleration/ } \\
\text { Deceleration }\end{array}$ & $\begin{array}{l}\text { Monitoring } \\
\text { of Driving } \\
\text { Environment }\end{array}$ & $\begin{array}{l}\text { Fallback } \\
\text { Performance } \\
\text { of Dymamic } \\
\text { Drlving Task }\end{array}$ & $\begin{array}{l}\text { System } \\
\text { Capability } \\
\text { (Driving } \\
\text { Modes) }\end{array}$ \\
\hline \multicolumn{7}{|c|}{ Human drfver monittors the drlving environment } \\
\hline & $\begin{array}{l}\text { No } \\
\text { Automation }\end{array}$ & $\begin{array}{l}\text { the full-time performance by the human driver of all } \\
\text { aspects of the dynamic dhinging task, even when enhanced } \\
\text { by warning or intervention systems }\end{array}$ & Human driver & Human driver & Human driver & $n / a$ \\
\hline & $\begin{array}{c}\text { Ditver } \\
\text { Asslstance }\end{array}$ & $\begin{array}{l}\text { the driving modespecific execution by a driver assistance } \\
\text { system of either steering or accelcration/deceleration using } \\
\text { information about the driving environment and with the } \\
\text { expectation that the human dhiver perform all remaining } \\
\text { aspects of the dynamic driving task. }\end{array}$ & $\begin{array}{l}\text { Human diviver } \\
\text { and system }\end{array}$ & Human diviver & Human driver & $\begin{array}{l}\text { Some driving } \\
\text { modes }\end{array}$ \\
\hline 2 & $\begin{array}{l}\text { Partial } \\
\text { Automation }\end{array}$ & $\begin{array}{l}\text { the driving mode-specific execution by one or more driver } \\
\text { assistance systems of both steering and acceleration/ } \\
\text { deceleration using information about the driving } \\
\text { environment and with the expectation that the human } \\
\text { driver perform all remaining aspects of the dynamic driving } \\
\text { task }\end{array}$ & Syitem & Human driver & Human driver & $\begin{array}{l}\text { Somedriving } \\
\text { modes }\end{array}$ \\
\hline \multicolumn{7}{|c|}{ Antomated diving system (" "system") moniltors the drlving environment } \\
\hline 3 & $\begin{array}{l}\text { Conditional } \\
\text { Automation }\end{array}$ & $\begin{array}{l}\text { the ofriving mode-specific performance by an automated } \\
\text { driving system of all aspects of the dymamic driving task } \\
\text { With the expectation that the human dhiver will respond } \\
\text { appropriately to a request to intervene }\end{array}$ & System & Sytem & Human diver & $\begin{array}{l}\text { Some driving } \\
\text { moder: }\end{array}$ \\
\hline 4 & $\begin{array}{l}\text { High } \\
\text { Automation }\end{array}$ & $\begin{array}{l}\text { the driving mode-specific performance by an automated } \\
\text { driving system of all aspects of the dynamic driving task. } \\
\text { even if a human driver does not respond appropriately to a } \\
\text { request to intervene }\end{array}$ & System & System & Sratem & $\begin{array}{l}\text { Some driving } \\
\text { modes: }\end{array}$ \\
\hline 5 & $\begin{array}{l}\text { Full } \\
\text { Automation }\end{array}$ & $\begin{array}{l}\text { the full-time pertormance by an automated driving system } \\
\text { of all aspects of the dyamic olviving thask under all roadway. } \\
\text { and environmental conditions that can be managed by a } \\
\text { human dhiver }\end{array}$ & System & System & System & Alldring \\
\hline
\end{tabular}

*_Reprinted from @ 2014 SAE International. Retrieved from: https://www.sae.org/misc/pdfs/automated_driving.pdf. Reprinted with permission.

\subsection{Potential Societal Benefits}

Autonomous vehicles have the potential to offer several attractive benefits to society, such as a significant improvement in motor vehicle safety, potential advances in equity, and the potential to transform our built environment.

Firstly, given that $95 \%$ of motor vehicles accidents are attributable to human error, a complete transition to fully autonomous vehicles could potentially reduce the 1,800 fatalities and 9,500 serious injuries that occur each year in Canada (Transport Canada, 2014). Harnessing the 
positive benefits from autonomous vehicles to advance the public good while mitigating any negative impacts rests on our understanding of how consumers will adopt and use this nascent technology and how vehicle ownership structure may change.

Secondly, AVs may change our travel behaviors. The low cost of shared autonomous vehicles (SAVs) may provide more travel opportunities for people who could not otherwise operate or afford a vehicle. Autonomous vehicles may increase access for individuals who currently have limited mobility.

Lastly, autonomous vehicles have the potential to reshape our landscapes. The vehicles may enable more compact land uses and allow us to re-imagine previously underutilized spaces, such as parking lots or curbsides.

Nevertheless, the lessons we have learned from previous technologies suggest that the potential for transformation may not be realized. Notably, while transportation technologies such as the steam engine and the personal vehicle dramatically changed our cities, it remains unclear whether the electric car, the Hyperloop, drones, or monorails will ever become transformational. Just because a technology could yield significant social or individual benefits does not mean it will be used or adopted by consumers. Are AVs ever likely to live up to their potential? To better answer this question, policymakers need to understand how consumers will use and adopt this new technology if they want to maximize societal benefits.

\subsection{Role of Autonomous Vehicles}

Autonomous vehicles will likely be offered through two forms of ownership: private AVs (PAVs) and shared AVs (SAVs). PAVs will be similar to the conventional vehicle used today with a reduced burden of travel. Conversely, SAVs will be more akin to the service currently offered by Uber or taxis, with the lack of human operation being the primary difference.

SAVs offer the promise of affordable and convenient travel and could potentially reduce road congestion by transporting a higher number of passengers per vehicle (Krueger, Rashidi, \& Rose, 2016). SAVs have the potential to benefit society if government policy and private interests can be reconciled in such a way that allow these private services to successfully integrate into the existing transportation network. SAVs may provide enhanced mobility options for individuals 
who currently have limited access to a personal vehicle (Anderson, et al., 2014; Shaheen \& Cohen, 2012) and could help the elderly become more mobile (Fagnant \& Kockelman, 2015) (Anderson, et al., 2014).

\subsection{Emerging Technology Lessons}

How we engage in and function within our cities not only depends on travel opportunities and individual characteristics but also upon the continuously evolving technologies that change how we think, behave, and transform our travel patterns. Private sector innovation in information sharing coupled with user-centered products have significantly increased how much consumers engage with digital technologies: with a few clicks and swipe of a screen people can now look up directions, hail an Uber, or book a flight to name but a few examples. Consumer adoption of previous emerging technologies has varied drastically. However, lessons learned from the established links between transportation technologies, urban function, and urban spatial structure (Alonso, 1964; Von Thunen, 1826; Christaller, 1933) provide examples of how innovations can alter behavior and reshape landscapes. Examples include how transit has shaped suburbanization (Warner Jr., 1962) and led to more productive and denser cities (Chatman \& Noland, 2013), while freeways have induced less dense urban spatial structures (Baum-Snow, 2007). 


\section{Chapter 2: Existing Literature}

\subsection{The Potential Benefits, Costs, and Impacts}

The costs and benefits surrounding the adoption of self-driving vehicles are poorly understood and two veins of research engender the debate: an optimist and a pessimist view. Further research is needed on the policy implications of autonomous vehicles given how wide ranging their impact will be. The academic literature remains divided on some of the central policy questions that pertain to AVs, such as whether they will lead to denser urban cores and their overall impact on vehicle kilometres travelled (VKT) (Fagnant \& Kockelman, 2015).

Fagnant and Kockelman (2015) argue that autonomous vehicles will improve safety and reduce Greenhouse Gas (GHG) emissions but also note that AVs may spur additional travel demand. Moreover, Litman (2017) purports that cities will become denser and more compact, driver stress will be reduced, and private vehicle ownership will decrease. Cities could become denser due to the decreased need for parking in the downtown core and the ability for cars to travel and park closer together. The adoption of the autonomous vehicle may also present an opportunity to capitalize on car sharing to reduce personal vehicle ownership. Fagnant and Kockelman (2015) also suggest that SAVs may reduce average trip costs by up to $85 \%$ depending upon on advancements in technology and fleet pricing mechanisms. In addition, SAVs may complement the current public transportation system by offering affordable options to solve the last mile/first mile problem. Vehicles could self-direct themselves to locations for individual pick up (Shaheen $\&$ Cohen, 2012). In turn, the need for parking would decrease and could potentially result in more usable land in central business districts. Vehicle to vehicle technology (V2V) and vehicle to infrastructure (V2I) could also improve driving efficiency, traffic optimization, and safety (Krueger, Rashidi, \& Rose, 2016).

Conversely, Anderson et al., (2014) argues that spatial land use patterns may become more dispersed with firms locating outside of the city core because travel is easier. Further, residents may choose to locate further away from the city because their commute is more enjoyable (they can now watch TV, do work, et cetera.) depending on how they value time savings and travel costs. GO Transit, a commuter rail and bus service operating in the GTHA, has occasionally been criticized for enabling urban sprawl by allowing commuters to live far away from their 
place of work without having to endure a long motor vehicle commute. Autonomous vehicles could potentially amplify this problem by reducing the personal cost of living further away. These sorts of decisions may be largely be dependent upon individual characteristics and preferences.

\subsection{Public Opinion and Preferences}

Understanding how consumers will respond and engage with both PAVs and SAVs is integral to understanding what their impact will be on our communities and travel patterns. To date, very few studies have explored how consumers will react to AV technology, and the impacts of autonomous vehicles remain uncertain. The studies that have been conducted have found that consumers who are familiar with automation in vehicles (Shoettele and Sivak, 2014; Kyriakidis et al., 2015), have high rates of travel or travel long distances (Kyriakidis et al., 2015; Krueger, Rashidi, and Rose, 2016; Robertson, Meister, and Vanlaar, 2016) who have experienced vehicle collisions (Bansal, Kockelman, and Singh, 2016), live in urban areas (Bansal, Kockelman, and Singh, 2016; Lavieri et al., 2017; Consultant J.D Power, 2013), or are technologically adept (Bansal, Kockelman, and Singh, 2016; Zmud, Sener \& Wagner, 2016; Lavieri et al., 2017) are more willing to adopt new technologies. The impact of demographic features, such as age and income are not clearly understood and current studies disagree on whether a relationship exists (Zmud, Sener \& Wagner, 2016; Bansal, Kockelman, and Singh, 2016; Krueger, Rashidi, and Rose, 2016; Lavieri et al., 2017; Deloitte, 2016; J.D Power, 2013). The existing literature on public opinion and preferences towards autonomous vehicles is discussed in-depth below.

Shoettle and Sivak (2014) deployed a consumer survey to approximately 1500 respondents across the United Kingdom, the United States, and Australia to explore how people would engage with autonomous vehicles. $25 \%$ of respondents in the US were willing to spend an additional $\$ 2000$ or more for a fully self-driving vehicle, while $25 \%$ of respondents in the UK and Australia would be willing to pay at least $\$ 1710$ and $\$ 2350$ respectively. Overall perceptions of AVs were positively correlated with an individual's level of exposure to less advanced forms of automation, such as adaptive cruise control or lane assist (Schoettle \& Sivak, 2014). Interestingly, their study demonstrates that a positive relationship exists between previous exposure to some form of automation and an individual's willingness to pay for a fully 
autonomous vehicle (Schoettle \& Sivak, 2014).

Further supporting the finding that individuals who already use a personal vehicle with some level of automation are willing to pay more for a fully autonomous vehicle is the research by Kyriakidis et al. (2015). Five thousand respondents across 109 countries were surveyed using a crowd-sourcing approach. Respondents indicated they would be willing to pay up to $\$ 7000$ for Level 4 AVs (which was defined as fully automation). Furthermore, vehicles miles travelled (VMT) was positively correlated with willingness to pay, an observation that may indicate that autonomous vehicles will have less of an impact in areas located closer to the downtown core.

Bansal, Kockelman, and Singh (2016) deployed an online survey to approximately 300 individuals to explore opinions related to autonomous vehicles. Neighbourhood associations were contacted and asked to pass on a survey link to their members. ${ }^{1}$ Average willingness to pay for a fully autonomous vehicle was estimated at just over \$7,253 USD. The results indicated that individuals who have experienced more vehicle collisions, identify as male, are technologically savvy, and live urban areas have a greater interest in and higher WTP for shared autonomous vehicles.

Zmud, Sener \& Wagner (2016) also surveyed 556 Austinites to explore consumer interest in using autonomous vehicles. Their results indicated that $50 \%$ of respondents were interested in using AVs; the other half of respondents were not interested in AV technology. Contrary to the findings of Bansal, Kockelman, and Singh (2016) age and income were not statistically significant for WTP for PAVs. Knowledge of technology and having a physical disability that hinders driving were positively correlated with an individual's intent to use autonomous vehicles. Interestingly, the results lend evidence that demographic characteristics are less important relative to lifestyle and psychographic characteristics. However, the authors also indicated that desire to feel in control showed no statistical significance with intent to use an autonomous vehicle.

\footnotetext{
${ }^{1}$ To our knowledge, this is the first study to estimate WTP using demographics, built-environment characteristics, and travel characteristics.
} 
Lavieri et al. (2017) further lend support to the notion that lifestyle characteristics and personality can explain individual interest in autonomous vehicles. Their results demonstrate that lifestyle factors, such as familiarity with technology and self-identifying as an individual who lives a green lifestyle, are good predictors of who will be an early adopter of AV technology. Similar to the findings in Bansal, Kockelman, and Singh (2016), these results indicate that residents who live in urban areas are more likely to adopt AVs.

Krueger, Rashidi, and Rose (2016) deployed a stated choice survey to approximately 400 residents in the major urban areas of Australia to understand consumer behaviour in response to SAVs. Their results indicated that travel cost, travel time, and waiting time will be critical determinants of individual willingness to use SAVs. Moreover, younger respondents and individuals who currently travel using multiple modes were the most interested in using this AV ownership model.

Deloitte (2017)lends further credence to the notion that younger individuals are more likely to use autonomous vehicles. Over 22,000 consumers in 17 countries were surveyed and their results indicated that younger people are willing to pay up to $\$ 1600$ for self-driving features. In addition, this report also demonstrated that willingness to pay varies over different geographies and age generations.

Consultant J.D Power (2013)conducted an online survey of 17,400 vehicle owners that demonstrated that only one in five consumers were interested in using a fully autonomous vehicle. Their findings also revealed that younger males living in urban areas were the most willing to pay for autonomous vehicle technology. This is consistent with previous research on predicting the adoption of autonomous vehicles (Lavieri, et al., 2017; Bansal, Kockelman, \& Singh, 2016).

More recently, J.D Power (2016) undertook another online survey to measure consumer responses for autonomous vehicles. In total, 7,900 respondents consisted of consumers who had purchased or leased a new vehicle in the past five years. The results suggest that younger respondents are more likely to trust autonomous vehicle technology, a link associated with level 
of interest in automotive features. The authors also found that $32 \%$ of younger respondents would pay $\$ 3,000$ or more for the technology.

In line with findings that younger respondents are willing to pay more is the research by Daziano, Sarrias, and Leard (2016), who surveyed 1260 individuals on questions related to willingness to pay for autonomous features. Their results indicated that the average household is willing to pay an additional $\$ 4900$ for a fully autonomous vehicle. In addition, many respondents were willing to pay above $\$ 10,000$ for full automation and respondents who were aware of autonomous vehicles were willing to pay a higher premium.

Robertson, Meister, and Vanlaar (2016) surveyed approximately 2600 respondents stratified across Canada. Their results indicated that less than one-fifth of individuals strongly believe that they would use a fully autonomous vehicle. Unsurprisingly, respondents who drove longer distances on average were more likely to report that they would use a self-driving vehicle. Older respondents were also reported to be less interested in autonomous vehicle when compared to public transit. The results also indicated that current mode share was a predictive indicator of autonomous vehicle use. For example, $15 \%$ of respondents who cycled or walked to work and $33 \%$ of people who used public transit reported that they would switch to a self-driving vehicle if it could return home or park itself (Robertson, Meister, \& Vanlaar, 2016).

\subsection{Consumers' Individual Choice}

While technology can enable more productive cities (Chatman \& Noland, 2013), these advances are contingent upon consumer acceptance. Consumer adoption and use of technology is complicated. Rogers (1983) provided lessons on how, why, and at what rate consumers and which consumers would adopt new products. He segmented consumers and their characteristics into sections: Innovators, Early Adopters, Early Majority, Late Majority, and Laggards (Rogers, 1983). He also suggests that adoption can be divided into different stages: the knowledge stage, persuasion stage, decision stage, implementation stage, and confirmation stage (Rogers, 1983). Complementing this model is previous theoretical work (Fishbein \& Azjen, 1975) that demonstrates how function of attitudes, subjective norms, and perceived behavioural control 
determinants of the Theory of Planned behaviour, influence intention to engage in an activity. Finally, according to Technology Adoption Models, perceived usefulness and ease of use can explain how use and adoption occur (Davis, 1989).

The diffusion and mass adoption of AVs will stem from individual decisions that are based on a variety of different factors, all of which ultimately compare the benefits and risks of using this new technology. While perceived risks are low for a mobile application such as Google Maps or Uber, perceptions of risk may influence adoption rates (Davis, 1989). One such example of a new technology that may provide teachable lessons is the hybrid electric vehicle. According to Axsen, Mountain, and Jaccard (2009) social acceptance of the hybrid electric vehicle resulted from a combination of educational efforts, increased credibility, and individuals learning from the experiences of others. Conversely, barriers to adopting EV technology included lack of knowledge by potential adopters, high-risk perceptions, and high initial costs (Diamond, 2009). If technology awareness is positively correlated with willingness to pay for autonomous vehicles then there may be a role for government to work with private sectors partners to increase awareness and demonstrate that AV technology is safe to use. Evidence suggests that many people also gain pleasure from feeling in control in their vehicles (Hartig, 2007; Gatersleben, 2007). Further lending support to the notion that the use of a private vehicle is influenced by more than utility-based understanding principles has been the finding that cars represent status symbols expressing autonomy, freedom, and flexibility (Steg, 2005).

Predicting which consumers are more likely to adopt AVs will allow governments to proactively respond with appropriate policy and regulations and perhaps target certain market segments. Policymakers should be focusing on the key hinge points that may enable mass adoption of AV technology. Hinge points include vehicle ownership model, level of automation, and level of diffusion.

\subsection{Government Action}

An uncomfortable relationship exists between the private and public sector that we have been historically unprepared to manage (Guerra, 2015). This avenue of tension may either help or 
hinder the public interest. If previous lessons on integrating technology into urban planning practice provide guidance for AVs, policymakers may either ignore new opportunities or conservatively protect existing services from disruption. Reasons for public policymakers to regulate, subsidize, or shape AV production and dissemination can vary from economic development goals, political marketing, city building, and improving transportation. Ignoring or misunderstanding how consumers will use this technology could severely limit opportunities for public policy to advance collective social goals in transportation policy. This raises the question of the role between the public sector and the private sector in advancing a process that can harness the collective good for AV technology while mitigating the negative consequences. Opportunities for public sector intervention resulting in the diffusion of autonomous vehicles emerge from inequities and inequality, inefficiencies, environmental issues, and providing transportation choices for the public. To manage or help internalize externalities, the public sector's role in policy can be broadly categorized into three alternatives: supply, regulate, or subsidize and tax.

Supply: a transition towards autonomous vehicles will necessitate investment in road infrastructure. Vehicle to infrastructure (V2I) through LTE technology could amplify the benefits of AV adoption by maximizing traffic flow. Dedicated curb space for SAV pick up/drop off is another investment that could encourage their adoption.

Regulate: safety concerns will need to be addressed through government regulation and monitoring. Existing regulations governing ridesharing providers will need to be updated to reflect the changing nature of these services. The use of smartphone apps and cellular phone data collection also represents a significant opportunity for the integration of existing and developing AV technologies. Already today, significant aspects of Information Technology Services (ITS) that used to be the realm of government have been taken over by private industries utilizing mobile technologies such as LTE. However, policymakers should also be wary of allowing a single corporation such as Uber or Google to dominate the autonomous vehicle market.

Subsidize or Tax: governments can direct adoption of autonomous vehicles using subsidies and taxation. For example, a congestion charge or parking levy could help mitigate the induced demand for private vehicle travel that PAVs might generate (Fagnant \& Kockelman, 2015). In 
addition, directly subsidizing SAV trips to/from public transit could allow governments to phase out feeder bus routes and focus on delivering high quality rapid transit networks that can compete with PAVs on cost and trip duration.

\subsection{Research Gap}

Historically, private-sector development and market penetration of new technology has been significantly faster than public sector planners: public policy has lagged and frequently reflected an aging view of how technology, people, and policy intersect to create functioning cities. For instance, the introduction of the Ford Model $\mathrm{T}$ in the early $20^{\text {th }}$ century radically transformed the way people lived in and interacted with the built environment (Zon \& Ditta, 2016). The mass adoption of the private vehicles resulted in the rapid expansion of highways and dispersed settlement patterns (Zon \& Ditta, 2016). Current transportation planning efforts remain rooted in predict and provide infrastructure investment approaches based on current rapid transit and automobile technologies - technologies that are more than 100 years old. Despite forays into information technology, public planners (Guerra, 2015) have been reluctant to prepare for emerging or disruptive technologies.

While some academic literature currently exists to provide insight into how consumer preferences will impact autonomous vehicles, researchers have a very limited understanding of how demographic characteristics, individual preferences, travel behavior patterns, and land use characteristics affect the adoption of autonomous vehicles. Considerable uncertainty is rooted in how consumers will react to new technology and how much they are willing to pay.

This paper will investigate how consumers in the Greater Toronto-Hamilton area (GTHA) may respond to fully autonomous vehicles (level 5). The speed at which an autonomous vehicle future unfolds is based on three main features: technological engineering challenges, regulatory barriers, and consumer preferences - the last of which is the focus of this research. This research seeks to understand what conditions and characteristics GTHA consumers either adopt privately held automated vehicles (PAVs) or use shared AVs (SAVs) once the technology becomes readily available. A consumer survey was deployed to explore the extent to which characteristics of AVs and the mobility system, prices, household/individual characteristics, land use characteristics, commuting and travel behaviour, and individual preferences/technology influence AV adoption 
and the use of PAVS or SAVs. This survey represents a novel contribution to the academic literature based on its sample size and the comprehensive survey design that it employs. In addition, the survey has the ability to help shape transportation planning in the GTHA by providing an indication of how consumer adoption of AVs will unfold in the area. 


\section{Chapter 3: Research Design}

\subsection{Methods}

The data were collected via deployment of an online survey administered by Research Now in November 2016. A total of 3201 respondents completed the survey. Prospective survey participants on Research Now's panel of over 450,000 Canadians between the ages of 18 and 75 and who reside in the Greater Toronto and Hamilton Area were contacted by email. The sample was stratified to reasonably represent the Greater Toronto and Hamilton Area; areas sampled include the City of Toronto, City of Hamilton, Region of Peel, Region of York, Region of Durham, and the Region of Halton. The City of Toronto is further subdivided into four districts: Toronto and East York (District 1), Etobicoke and York (District 2), North York (District 3), and Scarborough (District 4). To correct for under-represented young males and over-represented individuals with high incomes the sample was weighed proportionately according to age, sex, and income to scale to Statistics Canada (2011).

To explore consumer preferences for the adoption and use of autonomous vehicles, the survey established the following background information about individual respondents: demographic characteristics, employment status, place of residence and household characteristics, individual preferences, vehicle ownership, recent travel, and commuting behaviour to work/school. Respondents were asked questions specific to autonomous vehicles such as: individual preferences towards AV technology, prospective travel using an AV, how AVs will influence household location choices, and the relationship between AVs and public policy. 


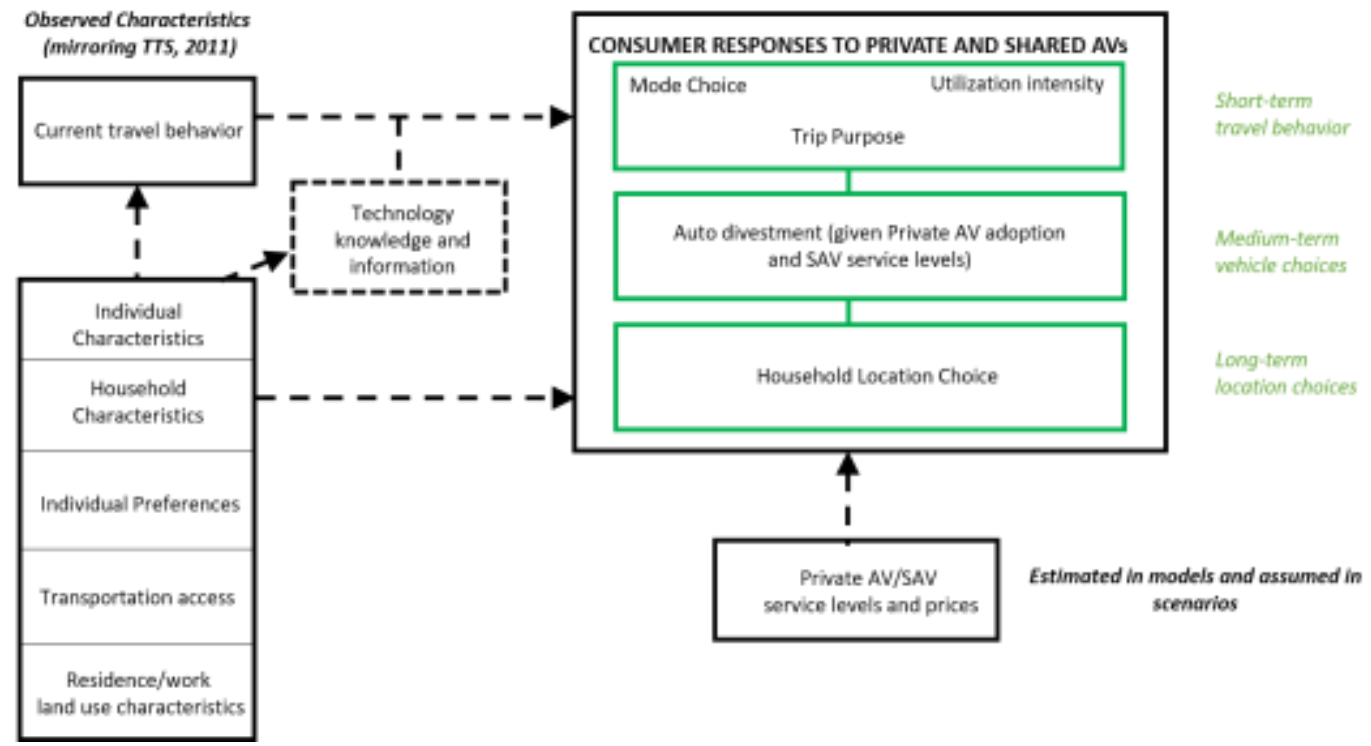

\subsection{Dependent Variable Questions}

The following questions will be explored using ordered logit models:

If Uber-style shared driverless cars can pick you up and drive you anywhere in the Greater Toronto Area for a price of $\$ 0.50 / 1.00 / 1.50$ per $\mathrm{km}$, how often would you use this service for commuting or other trip purposes (not including accessing public transit)?

Never

Less than once per month

Between one and 3 times a month

At least once a week

Daily

If you are purchasing a new vehicle, how much more would you be willing to pay for it to be available as a fully driverless car as opposed to a conventional car?

I would not buy a driverless car

Less than $\$ 1000$

\$1000-\$4999

$\$ 5,000$ to $\$ 9,999$

$\$ 10,000$ to $\$ 14,999$

More than $\$ 15,000$

\subsection{Modelling Estimation}

This paper models individual willingness to pay for Level 5 automation and how often an individual would be interested in using a shared autonomous vehicle at three different price points $(\$ 0.50 / \$ 1.00 / \$ 1.50$ per $\mathrm{km})$ as a function of individual and household characteristics using 
ordinal logistic regression model specifications. These price points were selected because the cost of driving a personal vehicle is approximately $\$ 0.54$ per $\mathrm{km}$; testing consumer preferences at these three price points indicates whether the cost of an SAV needs to be equivalent to a personal vehicle to enable consumer adoption. Ordered logistic regressions were used because the dependent variables were categorical responses that can be ranked. The validity of these model results rely upon the proportional odds assumption (sometimes referred to as the parallel regression assumption): the relationship between the coefficient values and the different categories of the response variables is assumed equal for all categories. The ordinal logistic coefficients can be interpreted as follows: ceteris paribus, a one-unit increase in the independent variable corresponds to a change in the dependent variable by its respective regression coefficient in the ordered log-odds scale.

A stepwise modelling approach was employed to reflect the problem of multicollinearity. The level of correlation between the included independent variables reduces the accuracy of individual coefficient estimates. The model is still unbiased but the standard errors are not accurate and there is a lower likelihood of rejecting the null hypothesis. The stepwise approach does not eliminate multicollinearity but it provides an indication of where the relationships exist between the independent variables. Limited variation in coefficient estimates across model iterations strengthens their credibility, though the problem of omitted variable bias continues to exist. Each model was tested using five iterative specifications that build upon each other. The specifications are grouped into four categories based on the explanatory variables that they contain: (1) Individual/Household Characteristics, (2) Land Use, (3) Commuting/Travel Behaviour, and (4) Preferences \& Technology. Each specification contains the explanatory variables that were included in prior models. For example, (3) introduces commuting/travel behaviour variables but also contains the individual/household characteristics and land use variables. Land Use characteristics were calculated by extracting job density and population information at an aggregated level using GIS. 


\section{Chapter 4: Descriptive Statistics}

Table 1 summarizes the individual characteristics of the sample respondents that have been categorized into four groups: household/individual characteristics, land use characteristics, commuting and travel behaviour, and individual preferences/technology. Land use characteristics are not included in this table because the heterogeneous frequency distribution did not lend itself to meaningful classification. These variables were used as predictors in every model specification. Observations have been weighted by age, gender, and household income to correct for oversampling and under sampling of several demographic groups.

Table 1: Frequency Counts of Explanatory Variables

\begin{tabular}{|c|c|c|c|c|c|c|}
\hline \multicolumn{7}{|c|}{ Household and Individual Characteristics } \\
\hline Age & $18-34$ & $35-54$ & $55-75$ & & & \\
\hline & 1011 & 1128 & 1062 & & & \\
\hline $\begin{array}{l}\text { Household } \\
\text { Income }\end{array}$ & $\begin{array}{l}\$ 0 \text { to } \\
\$ 14,999\end{array}$ & $\begin{array}{l}\$ 15,000 \text { to } \\
\$ 39,999\end{array}$ & $\begin{array}{l}\$ 40,000 \text { to } \\
\$ 59,999\end{array}$ & $\begin{array}{l}\$ 60,000 \\
\text { to } \\
\$ 99,999\end{array}$ & $\begin{array}{l}\$ 100,000 \\
\text { to } \\
\$ 124,999\end{array}$ & $\begin{array}{l}\$ 125,000 \\
\text { to } \\
\$ 175,000\end{array}$ \\
\hline & 78 & 316 & 440 & 796 & 385 & 361 \\
\hline & $\begin{array}{l}\$ 175,000 \\
\text { and above }\end{array}$ & $\begin{array}{l}\text { Prefer not to } \\
\text { answer }\end{array}$ & I don't know & & & \\
\hline & 307 & 429 & 89 & & & \\
\hline Gender & Female & Male & Other & & & \\
\hline & 1686 & 1501 & 14 & & & \\
\hline $\begin{array}{l}\text { Physical } \\
\text { Disability }\end{array}$ & $\begin{array}{l}\text { Strongly } \\
\text { disagree }\end{array}$ & Disagree & $\begin{array}{l}\text { Neither } \\
\text { disagree or } \\
\text { agree }\end{array}$ & Agree & $\begin{array}{l}\text { Strongly } \\
\text { agree }\end{array}$ & \\
\hline & 2175 & 508 & 204 & 192 & 122 & \\
\hline $\begin{array}{l}\text { Driver } \\
\text { Collisions }\end{array}$ & None & 1 & 2 & 3 & $4+$ & NA \\
\hline & 1441 & 785 & 552 & 251 & 160 & 12 \\
\hline $\begin{array}{l}\text { Passenger } \\
\text { Collisions }\end{array}$ & None & 1 & 2 & 3 & $4+$ & NA \\
\hline & 1996 & 781 & 266 & 93 & 53 & 12 \\
\hline $\begin{array}{l}\text { Household } \\
\text { Size }\end{array}$ & 1 & 2 & 3 & 4 & 5 & $6+$ \\
\hline & 573 & 1190 & 652 & 518 & 186 & 82 \\
\hline \# of Children & None & 1 & 2 & 3 & 4 & $5+$ \\
\hline & 2412 & 458 & 257 & 52 & 14 & 8 \\
\hline
\end{tabular}




\begin{tabular}{|c|c|c|c|c|c|c|}
\hline \multicolumn{7}{|c|}{ Commuting and Travel Behaviour } \\
\hline Vehicle Cost & no vehicle & $\begin{array}{l}\text { less than } \\
\$ 15,000\end{array}$ & $\begin{array}{l}\$ 15,000- \\
\$ 30,000\end{array}$ & $\begin{array}{l}\$ 30,000- \\
\$ 45,000\end{array}$ & $\begin{array}{l}\$ 45,000- \\
\$ 60,000\end{array}$ & $\begin{array}{l}\text { more than } \\
\$ 60,000\end{array}$ \\
\hline & 341 & 539 & 1222 & 745 & 263 & 91 \\
\hline \multirow[t]{2}{*}{ \# of Vehicles } & no vehicle & 1 & 2 & 3 & 4 & $5+$ \\
\hline & 341 & 1428 & 1120 & 240 & 57 & 15 \\
\hline \multirow[t]{4}{*}{$\begin{array}{l}\text { Commute } \\
\text { Mode }\end{array}$} & $\begin{array}{l}\text { Auto } \\
\text { (Driver - } \\
\text { Alone) }\end{array}$ & $\begin{array}{l}\text { Auto (Driver } \\
\text { - Passengers) }\end{array}$ & $\begin{array}{l}\text { Auto } \\
\text { (Passenger) }\end{array}$ & Taxi/Uber & Motorcycle & Walk \\
\hline & 1356 & 123 & 60 & 27 & 2 & 107 \\
\hline & Bike & GO Train & $\begin{array}{l}\text { Public } \\
\text { Transit }\end{array}$ & $\begin{array}{l}\text { Don't } \\
\text { Commute }\end{array}$ & & \\
\hline & 19 & 128 & 375 & 1004 & & \\
\hline \multirow[t]{2}{*}{$\begin{array}{l}\text { Typical } \\
\text { Commute } \\
\text { Time }\end{array}$} & $\begin{array}{l}\text { Don't } \\
\text { Commute }\end{array}$ & $1-19 \min$ & $20-29 \min$ & $\begin{array}{l}30-39 \\
\min \end{array}$ & $40-59 \mathrm{~min}$ & $60+\min$ \\
\hline & 1023 & 516 & 394 & 412 & 455 & 401 \\
\hline \multirow[t]{2}{*}{$\begin{array}{l}\text { Dist. Travelled } \\
\text { Yesterday }\end{array}$} & None & $1-19 \mathrm{~km}$ & $20-29 \mathrm{~km}$ & $30-40 k m$ & $40-59 \mathrm{~km}$ & $60+k m$ \\
\hline & 681 & 789 & 469 & 277 & 394 & 591 \\
\hline \multirow[t]{2}{*}{$\begin{array}{l}\text { Monthly Uber } \\
\text { Use }\end{array}$} & Never & $\begin{array}{l}0-3 \text { in last } 30 \\
\text { days }\end{array}$ & 1 per week & $\begin{array}{l}\text { 2-4 per } \\
\text { week }\end{array}$ & 5 per week & $\begin{array}{l}\text { 6-7 per } \\
\text { week }\end{array}$ \\
\hline & 2469 & 580 & 87 & 45 & 13 & 7 \\
\hline \multicolumn{7}{|c|}{ Individual Preferences and Technology } \\
\hline \multirow[t]{2}{*}{$\begin{array}{l}\text { Vehicle Sense } \\
\text { of Control }\end{array}$} & $\begin{array}{l}\text { Strongly } \\
\text { Disagree }\end{array}$ & Disagree & Neither & Agree & $\begin{array}{l}\text { Strongly } \\
\text { Agree }\end{array}$ & \\
\hline & 57 & 184 & 765 & 1534 & 661 & \\
\hline \multirow[t]{2}{*}{$\begin{array}{l}\text { Vehicle Sense } \\
\text { of Freedom }\end{array}$} & $\begin{array}{l}\text { Strongly } \\
\text { Disagree }\end{array}$ & Disagree & Neither & Agree & $\begin{array}{l}\text { Strongly } \\
\text { Agree }\end{array}$ & \\
\hline & 51 & 96 & 406 & 1563 & 1085 & \\
\hline \multirow[t]{2}{*}{$\begin{array}{l}\text { Google Car } \\
\text { Knowledge }\end{array}$} & No & Unsure & Yes & & & \\
\hline & 1302 & 281 & 1618 & & & \\
\hline \multirow[t]{2}{*}{$\begin{array}{l}\text { Own a } \\
\text { Smartphone }\end{array}$} & No & Unsure & Yes & & & \\
\hline & 459 & 15 & 2727 & & & \\
\hline
\end{tabular}

\subsection{Household/ Individual Characteristics}

The age of survey respondents has been grouped into three intervals: 18-34, 35-54, and 55-75. Respondents below the age of 18 or above the age of 75 were not sampled. Age was modelled 
using interval dummy variables that roughly correspond to different stages of a typical lifecycle. Household income was also modelled using a set of dummy variables that correspond to commonly used income brackets. In addition, a separate dummy variable was included for respondents who were not comfortable disclosing their household income or who could not provide an accurate answer; omitting these non-responses would have decreased the sample size by $16 \%$. Gender was also modelled using dummy variables; the gender reference group of each model was respondents who self-identified as being female. Respondents indicated whether or not they have a physical disability using a five point scale that ranged from Strongly Disagree to Strongly Agree. The number of collisions while the respondent was a driver or passenger of a motor vehicle was a write-in response in the survey; as a result, a small number of outliers were flagged and the maximum number of collisions for either variable was arbitrarily set to 10 . Household size and the number of household members below the age of 15 were also write-in survey responses and a similar number of outliers were identified.

\subsection{Land Use Characteristics}

Several measures of land use characteristics were tested during the analysis of survey data, all of which relied upon forward sortation areas (FSAs) as the geographic location identifier for each observation: population density, internal job density, job density within a 5k radius, and job density within a 10k radius. However, only job density within a 10k radius proved to be statistically significant for any model specification that was tested and it was the only land use variable that was ultimately included.

\subsection{Commuting/Travel Behaviour}

Two measures of vehicle ownership were included in each model specification: ownership of at least one vehicle that cost over $\$ 30,000$ and the number of vehicles per adult household member. $23 \%$ of respondents indicated that they had previously purchased a vehicle for over $\$ 30,000$, a variable that was strongly correlated with household income. The average number of vehicles per household member was 0.69 ; however, the standard deviation of 0.43 indicates that the vehicle/household member ratio exhibits considerable variation. $6 \%$ and $17 \%$ of respondents 
indicated that they predominantly commute via GO commuter rail and public transit respectively. An additional $6 \%$ of respondents use walking or cycling as their primary means of transportation to/from work. The commuting mode reference group largely consists of respondents who commute as a driver or passenger of a motor vehicle; a very small number of reference group respondents utilize a motorcycle or taxi/Uber. The typical commute time of respondents was 36.04 minutes per day; given that this was a write-in response an arbitrary upper limit of 240 minutes was established to deal with a small number of outliers. The trip distance dummy variable indicates that $79 \%$ of respondents had travelled during the previous day. The monthly Uber use variables indicate that only $13 \%$ of respondents have used Uber in the last 30 days; however, Uber is currently only available in Toronto, a region that constitutes 1200 of the 3201 sampled respondents.

\subsection{Preferences \& Technology}

Two survey questions were included in the model specifications to provide a general indication of individual views on the act of driving a motor vehicle. $82 \%$ of respondents indicated that driving gives them a sense of freedom; furthermore, $68 \%$ of respondents indicated that driving gives them a sense of control. In addition, two survey questions were included to establish individual familiarity with technology. $41 \%$ of respondents had never heard of the Google car before taking the survey, a proportion that was remarkably consistent across age groups. Finally, an overwhelming majority of respondents (87\%) own a smartphone, a proportion that still allows for meaningful comparison with the non-owning reference group.

\subsection{Response Variables}

Table 2: Population-weighted Results for Response Variables summarizes the seven response variables that were modelled in this study: WTP for Level 5 automation and interest in using SAVs at three price points $(\$ 0.50 / \$ 1.00 / \$ 1.50$ per $\mathrm{km})$. Participants were provided with a description of a SAV and told that the total cost of driving a conventional car typically ranges between $\$ 0.37$ and $\$ 0.88$ before answer this set of questions. See Appendix A for survey instrument. 
Table 2: Population-weighted Results for Response Variables

\begin{tabular}{|c|c|c|c|c|c|c|}
\hline \multicolumn{7}{|c|}{ WTP for Level 5 Automation } \\
\hline Nothing & $<\$ 1000$ & $\$ 1000-\$ 4999$ & $\$ 5,000-\$ 9,999$ & $\$ 10-\$ 15 k$ & $>\$ 15,000$ & $N / A$ \\
\hline $27 \%$ & $13 \%$ & $22 \%$ & $14 \%$ & $7 \%$ & $8 \%$ & $10 \%$ \\
\hline \multicolumn{7}{|c|}{ SAV \$0.50 per km } \\
\hline Never & $<1 \mathrm{mth}$ & 1-3 per mth & At least once a week & Daily & & \\
\hline $32 \%$ & $31 \%$ & $24 \%$ & $11 \%$ & $3 \%$ & & \\
\hline \multicolumn{7}{|c|}{ SAV \$1.0 per km } \\
\hline Never & $<1 \mathrm{mth}$ & 1-3 per mth & At least once a week & Daily & & \\
\hline $49 \%$ & $31 \%$ & $14 \%$ & $5 \%$ & $1 \%$ & & \\
\hline \multicolumn{7}{|c|}{ SAV \$1.50 per km } \\
\hline Never & $<1 \mathrm{mth}$ & 1-3 per mth & At least once a week & Daily & & \\
\hline $65 \%$ & $24 \%$ & $8 \%$ & $3 \%$ & $1 \%$ & & \\
\hline \multicolumn{7}{|c|}{ SAV to Transit $\$ 0.50$ per km } \\
\hline Never & $<1 \mathrm{mth}$ & 1-3 per mth & $>1$ per week & Daily & & \\
\hline $42 \%$ & $30 \%$ & $17 \%$ & $8 \%$ & $4 \%$ & & \\
\hline \multicolumn{7}{|c|}{ SAV to Transit $\$ 1.0$ per $\mathbf{k m}$} \\
\hline Never & $<1$ mth & 1-3 per mth & At least once a week & Daily & & \\
\hline $57 \%$ & $26 \%$ & $11 \%$ & $5 \%$ & $1 \%$ & & \\
\hline \multicolumn{7}{|c|}{ SAV to Transit $\$ 1.50$ per km } \\
\hline Never & $<1 \mathrm{mth}$ & 1-3 per mth & At least once a week & Daily & & \\
\hline $71 \%$ & $20 \%$ & $6 \%$ & $2 \%$ & $1 \%$ & & \\
\hline
\end{tabular}

For this question respondents were asked to indicate their willingness to pay (WTP) for Level 5 automation relative to a conventional motor vehicle. $27 \%$ of respondents indicated that they have no interest in buying a driverless car, a proportion that is highest (39\%) amongst the 55-75 age group. $51 \%$ of survey respondents are willing to pay a premium of $\$ 4,999$ or less for a vehicle with Level 5 automation; the number of respondents willing to pay a premium of $\$ 9,999$ for full 
automation drops to $29 \%$. Only $8 \%$ of respondents would be willing to pay an additional $\$ 15,000$ or more for a personal autonomous vehicle. The distribution of survey responses provides some indication that vehicle cost will be a strong determinant of PAV adoption rates in the GTHA. Roughly a third of respondents are only willing to pay a small premium (less than $\$ 5,000$ ) for Level 5 automation; even amongst households with a combined income of $\$ 125,000$ or more only $38 \%$ were willing to pay an additional premium of $\$ 5,000$ or more for AV functionality. It is important to note that respondents who had indicated in an earlier survey question that they were very uninterested in AVs (10\% of the sample) were not asked this question.

The first set of SAV questions was asked sequentially to establish how sensitive respondents were to the price at which this service could potentially be offered. Respondents were asked the following question: If Uber-style shared driverless cars can pick you up and drive you anywhere in the Greater Toronto Area for a price of $\$ 0.50 / 1.00 / 1.50$ per $\mathrm{km}$, how often would you use this service for commuting or other trip purposes (not including accessing public transit)? Any individual who answered "never" at a particular price point was not asked the same question again at a higher price; these respondents were automatically coded as "never" for the subsequent SAV questions. Survey respondents were generally uninterested in regularly using a SAV service even at the lowest price point. Only $3 \%$ of respondents indicated that they would use an SAV every day at $\$ 0.50 \mathrm{~km}$; amongst residents of Toronto, who should be more familiar with ride sharing services because it is the only GTHA jurisdiction where Uber currently operates, only $3.4 \%$ of respondents stated that they would use an SAV service every day. $11 \%$ of respondents indicate that they would use a SAV every week at $\$ 0.50$ per km but that number drops to $5 \%$ at a price point of $\$ 1.00$ per $\mathrm{km}$. At a price of $\$ 1.50$ per $\mathrm{km}$, very few respondents were interested in using an SAV service at any frequency. The proportion of residents who would use an SAV service at least once a month is $38 \%$ and $12 \%$ at price points of $\$ 0.50$ and $\$ 1.50$ per km respectively; the marginal price of a SAV will largely dictate how many residents choose to use this service. Overall, results seem to indicate that many respondents view an SAV service as a substitute for occasional taxi/Uber use rather than a potential replacement of their personal motor vehicle. 


\section{Chapter 5: Results}

\subsection{WTP for Level 5 Automation}

Table \#3 summarizes the ordered logistic regression model results for respondent WTP for Level 5 Automation. The stepwise approach allows us to observe how the coefficient values change once additional variables are included in the regression. The results indicate that, all else equal, the following characteristics of respondents are related to willingness to pay a higher premium for a fully autonomous vehicle: respondents who self-identify as male, have a household income of at least $\$ 60,000$ a year, live in areas that have a higher job density within a 10k radius of their dwelling, have paid more than $\$ 30,000$ for a personal vehicle, travel to work using GO commuter rail, travelled at least $1 \mathrm{~km}$ during the previous day, use Uber, or own a smartphone.

Conversely, respondents between the age of 35 and 75 and respondents who had not heard of the Google car prior to taking the survey were willing to pay a lower price premium for Level 5 automation. Household income between $\$ 100,000$ to $\$ 175,000$ per year loses its statistical significance in models (4) and (5) once Commuting/Travel Behaviour is included in the regression; this can likely be explained by the fact that owning a $\$ 30,000$ or more vehicle is correlated with household income $r(2873)=0.44, \mathrm{p}<0.05$, and only $32 \%$ of sampled GO train commuters have household incomes that are lower than $\$ 100,000$ per year.

However, households earning between $\$ 60,000$ and $\$ 100,000$ per year and those who earn over $\$ 175,000$ per year are still, ceteris paribus, willing to pay a higher premium for a personal $\mathrm{AV}$ even after controlling for vehicle cost, commute mode, and other factors such as commute time. In addition, self-identifying as male loses its statistical significance once Preferences \& Technology are included in the regression. Furthermore, the number of driver collisions was only statistically significant in model (1) but did not have sufficient explanatory power in the other model iterations. The results would appear to indicate that driver collisions have no bearing on an individual's aversion towards operating a motor vehicle once other transportation and land use choices are considered. Alternatively, the number of driver collisions could be impacting individual location choice and transportation preferences. The insignificance of passenger collisions is perhaps less surprising given that the individual has no direct control in either an AV 
or a conventional vehicle.

Table 3: Willingness to Pay for Level 5 Automation

\begin{tabular}{|c|c|c|c|c|c|c|c|c|c|c|c|c|c|c|c|}
\hline $\begin{array}{c}\text { WTP for Level } 5 \\
\text { Automation }\end{array}$ & (1) & & & (2) & & & (3) & & & (4) & & & (5) & & \\
\hline & Coef & Std.E & t-stat & Coef. & Std.E & t-stat & Coef & Std.E & $t$-stat & Coef & Std.E & t-stat & Coef & Std.E & t-stat \\
\hline Age (35-54) & $\begin{array}{c}- \\
0.328\end{array}$ & 0.082 & $\begin{array}{c}- \\
4.017\end{array}$ & $\begin{array}{c}- \\
0.335\end{array}$ & 0.082 & $\begin{array}{c}- \\
4.103\end{array}$ & $\begin{array}{c}- \\
0.346\end{array}$ & 0.082 & $\begin{array}{c}- \\
4.227\end{array}$ & $\begin{array}{c}- \\
0.263\end{array}$ & 0.093 & 2.834 & $\begin{array}{c}- \\
0.239\end{array}$ & 0.093 & $\stackrel{-}{2.556}$ \\
\hline Age (55-75) & $\begin{array}{c}- \\
0.851\end{array}$ & 0.096 & 8.822 & 0.851 & 0.097 & 8.813 & 0.861 & 0.097 & 8.912 & 0.403 & 0.135 & 2.982 & 0.342 & 0.138 & 2.487 \\
\hline HH Inc. (\$40k $><x<\$ 60 k)$ & 0.186 & 0.148 & 1.252 & 0.196 & 0.149 & 1.320 & 0.181 & 0.149 & 1.214 & 0.129 & 0.194 & 0.663 & 0.112 & 0.194 & 0.578 \\
\hline HH Inc. $(\$ 60 k<x<\$ 100 k)$ & 0.418 & 0.133 & 3.134 & 0.420 & 0.134 & 3.146 & 0.395 & 0.134 & 2.943 & 0.346 & 0.176 & 1.973 & 0.327 & 0.176 & 1.862 \\
\hline HH Inc. $(\$ 100 k<x<\$ 125 k)$ & 0.396 & 0.149 & 2.661 & 0.404 & 0.149 & 2.708 & 0.352 & 0.152 & 2.318 & 0.204 & 0.194 & 1.055 & 0.166 & 0.194 & 0.859 \\
\hline HH Inc. (\$125k - \$175k) & 0.479 & 0.153 & 3.133 & 0.475 & 0.153 & 3.104 & 0.402 & 0.156 & 2.579 & 0.171 & 0.197 & 0.864 & 0.122 & 0.198 & 0.618 \\
\hline HH Inc. (> \$175k) & 0.716 & 0.161 & 4.458 & 0.706 & 0.161 & 4.390 & 0.623 & 0.165 & 3.763 & 0.396 & 0.207 & 1.915 & 0.341 & 0.207 & 1.648 \\
\hline HH Income (Undisclosed) & $\begin{array}{c}- \\
0.034\end{array}$ & 0.147 & $\begin{array}{c}- \\
0.229\end{array}$ & $\begin{array}{c}- \\
0.025\end{array}$ & 0.147 & $\begin{array}{c}- \\
0.173\end{array}$ & $\begin{array}{c}- \\
0.059\end{array}$ & 0.148 & $\begin{array}{c}- \\
0.401\end{array}$ & $\begin{array}{c}- \\
0.214\end{array}$ & 0.196 & 1.090 & $\begin{array}{c}- \\
0.224\end{array}$ & 0.196 & $\begin{array}{c}- \\
1.142\end{array}$ \\
\hline Gender (Male) & 0.157 & 0.068 & 2.313 & 0.161 & 0.068 & 2.366 & 0.150 & 0.068 & 2.212 & 0.131 & 0.080 & 1.640 & 0.104 & 0.081 & 1.289 \\
\hline Gender (other) & 0.073 & 0.511 & 0.143 & $\begin{array}{c}- \\
0.126\end{array}$ & 0.512 & 0.246 & 0.090 & 0.514 & $\begin{array}{c}- \\
0.176\end{array}$ & 0.130 & 0.700 & $\begin{array}{c}- \\
0.185\end{array}$ & $\begin{array}{c}- \\
0.160\end{array}$ & 0.704 & $\begin{array}{c}- \\
0.227\end{array}$ \\
\hline Physically Disabled & 0.017 & 0.118 & 0.143 & 0.005 & 0.117 & 0.045 & 0.011 & 0.117 & 0.093 & $\begin{array}{c}- \\
0.235\end{array}$ & 0.156 & $\begin{array}{c}- \\
1.506\end{array}$ & $\begin{array}{c}- \\
0.251\end{array}$ & 0.156 & $\begin{array}{c}- \\
1.604\end{array}$ \\
\hline \# of Driver Collisions & $\begin{array}{c}- \\
0.114\end{array}$ & 0.064 & $\begin{array}{c}- \\
1.789\end{array}$ & 0.094 & 0.064 & 1.463 & 0.092 & 0.064 & 1.432 & 0.056 & 0.078 & 0.719 & 0.082 & 0.079 & $\begin{array}{c}- \\
1.037\end{array}$ \\
\hline \# of Passenger Collisions & 0.001 & 0.074 & 0.011 & 0.012 & 0.075 & 0.160 & 0.008 & 0.075 & 0.112 & $\begin{array}{c}- \\
0.035\end{array}$ & 0.089 & $\begin{array}{c}- \\
0.401\end{array}$ & $\begin{array}{c}- \\
0.059\end{array}$ & 0.089 & $\begin{array}{c}- \\
0.661\end{array}$ \\
\hline Household Size & $\begin{array}{c}- \\
0.011\end{array}$ & 0.079 & 0.140 & 0.026 & 0.079 & 0.329 & 0.016 & 0.093 & 0.170 & 0.008 & 0.108 & 0.076 & 0.010 & 0.108 & 0.088 \\
\hline Household under 15 & 0.046 & 0.088 & 0.519 & 0.036 & 0.088 & 0.404 & 0.048 & 0.093 & 0.521 & 0.050 & 0.106 & 0.474 & 0.063 & 0.106 & 0.596 \\
\hline Job Density (10k radius) & - & - & - & 0.193 & 0.049 & 3.979 & 0.177 & 0.050 & 3.547 & 0.170 & 0.063 & 2.684 & 0.154 & 0.064 & 2.413 \\
\hline Vehicle Cost (over $\$ 30 \mathrm{k}$ ) & - & - & - & - & - & - & 0.240 & 0.072 & 3.310 & 0.262 & 0.085 & 3.063 & 0.267 & 0.086 & 3.119 \\
\hline Vehicles per Adult & - & - & - & - & - & - & 0.199 & 0.213 & $\begin{array}{c}- \\
0.934\end{array}$ & 0.249 & 0.256 & $\begin{array}{c}- \\
0.973\end{array}$ & $\begin{array}{c}- \\
0.321\end{array}$ & 0.257 & $\begin{array}{c}- \\
1.251\end{array}$ \\
\hline Commute (GO Train) & - & - & - & - & - & - & - & - & - & 0.418 & 0.173 & 2.409 & 0.436 & 0.175 & 2.494 \\
\hline Commute (Public Transit) & - & - & - & - & - & - & - & - & - & 0.159 & 0.135 & 1.185 & 0.161 & 0.136 & 1.186 \\
\hline Commute (Bike/Walk) & - & - & - & - & - & - & - & - & - & 0.004 & 0.210 & 0.020 & $0 . \overline{0} 20$ & 0.212 & 0.096 \\
\hline Typical Commute Time & - & - & - & - & - & - & - & - & - & 0.004 & 0.058 & 0.062 & 0.001 & 0.058 & $\begin{array}{c}- \\
0.024\end{array}$ \\
\hline Travelled Yesterday & - & - & - & - & - & - & - & - & - & 0.379 & 0.145 & 2.605 & 0.346 & 0.146 & 2.366 \\
\hline Uber (have used) & - & - & - & - & - & - & - & - & - & 0.449 & 0.118 & 3.810 & 0.451 & 0.118 & 3.814 \\
\hline Uber(1-3 per mth) & - & - & - & - & - & - & - & - & - & 0.748 & 0.137 & 5.477 & 0.742 & 0.137 & 5.414 \\
\hline Uber (1 per week) & - & - & - & - & - & - & - & - & - & 0.825 & 0.210 & 3.920 & 0.834 & 0.212 & 3.944 \\
\hline Uber (2+ per week) & - & - & - & - & - & - & - & - & - & 0.554 & 0.260 & 2.133 & 0.497 & 0.262 & 1.895 \\
\hline Sense of Freedom & - & - & - & - & - & - & - & - & - & - & - & - & 0.148 & 0.134 & 1.098 \\
\hline Sense of Control & - & - & - & - & - & - & - & - & - & - & - & - & $\begin{array}{c}- \\
0.042\end{array}$ & 0.102 & $0 . \overline{-}$ \\
\hline Not aware of Google Car & - & - & - & - & - & - & - & - & - & - & - & - & 0.333 & 0.084 & 3.941 \\
\hline Own a Smartphone & - & - & - & - & - & - & - & - & - & - & - & - & 0.316 & 0.182 & 1.735 \\
\hline
\end{tabular}




\begin{tabular}{ccccccc}
\hline Residual Deviance: & 9455 & 9439 & 9427 & 6851 & 6830 \\
AIC: & 9495 & 9481 & 9473 & 6915 & 6902 \\
Sample Size: & 2873 & 2873 & 2873 & 1967 & 1967 \\
\hline
\end{tabular}

\subsection{Frequency of Use for a SAV $(\$ 0.50 / \$ 1.00 / \$ 1.50$ per $\mathbf{k m})$}

Tables \#4, \#5, and \#6 display the regression results for SAV usage at $\$ 0.50$ per $\mathrm{km}, \$ 1.00$ per $\mathrm{km}$, and $\$ 1.50$ per $\mathrm{km}$ respectively.

Table \#4 indicates that, ceteris paribus, respondents who have been in a higher number of vehicle collisions as a passenger, travel to work using GO commuter rail, public transit, or active transport, use Uber, and own a smartphone would use an SAV service more frequently if it is offered at $\$ 0.50$ per $\mathrm{km}$. Conversely, respondents with a higher number of vehicles per adult household member and respondents who had never heard of the Google car before would use an SAV service less frequently at this price point. Household income and job density within a 10k radius are both positively correlated with SAV frequency in models (1), (2), and (3) but the association disappears once Commuting/Travel Behaviour is included in the regression. In addition, demographic characteristics such as age and gender appear to have limited explanatory power once Commuting/Travel Behaviour and Preferences \& Technology are included. However, it should still be noted that age and self-identifying as male are negatively and positively correlated with SAV usage respectively in the first three iterations of the model.

Tables \#4 and \#5 display the second and third iterations of the SAV usage questions respectively. Ceteris paribus, respondents with a physical disability, who commute to work using GO or public transit, use Uber, believe that driving gives them a sense of control, and own a smartphone are more inclined to use an SAV service at a price point of $\$ 1.00$ per $\mathrm{km}$. Conversely, respondents who are in the 35-54 age group, have a higher number of vehicles per adult household member, spend more time commuting, believe that driving gives them a sense of freedom, and have never heard of the Google car are less inclined to use an SAV service at \$1.00 per $\mathrm{km}$. These relationships persist at a price point of $\$ 1.50$ per $\mathrm{km}$ with three exceptions: sense 
of control is no longer a statistically significant variable, having a higher number of children is positively correlated with SAV usage, and having been in a higher number of collisions as a driver has a negative association with use of an SAV service. 
Table 4: SAV Frequency of Use at $\$ 0.50$ per $\mathrm{km}$

\begin{tabular}{|c|c|c|c|c|c|c|c|c|c|c|c|c|c|c|c|}
\hline SAV Monthly \$0.50 & (1) & & & (2) & & & (3) & & & (4) & & & (5) & & \\
\hline & Coef & Std.E & $t$-stat & Coef & Std.E & $t$-stat & Coef & Std.E & $t$-stat & Coef & Std.E & $t$-stat & Coef & Std.E & t-stat \\
\hline Age (35-54) & -0.43 & 0.08 & -5.47 & -0.44 & 0.08 & -5.62 & -0.45 & 0.08 & -5.81 & -0.17 & 0.09 & -1.87 & -0.12 & 0.09 & -1.28 \\
\hline Age (55-75) & -0.72 & 0.09 & -7.86 & -0.71 & 0.09 & -7.76 & -0.71 & 0.09 & -7.77 & -0.01 & 0.13 & -0.11 & 0.105 & 0.13 & 0.781 \\
\hline HH Inc. $(\$ 40 k><x<\$ 60 k)$ & 0.3 & 0.13 & 2.35 & 0.314 & 0.13 & 2.452 & 0.363 & 0.13 & 2.81 & 0.102 & 0.17 & 0.61 & 0.075 & 0.17 & 0.445 \\
\hline HH Inc. (\$60k < x < \$100k) & 0.421 & 0.12 & 3.644 & 0.419 & 0.12 & 3.628 & 0.501 & 0.12 & 4.221 & 0.196 & 0.15 & 1.269 & 0.162 & 0.15 & 1.048 \\
\hline HH Inc. $(\$ 100 k<x<\$ 125 k)$ & 0.389 & 0.14 & 2.878 & 0.394 & 0.14 & 2.912 & 0.509 & 0.14 & 3.605 & 0.054 & 0.18 & 0.303 & -0.01 & 0.18 & -0.05 \\
\hline HH Inc. (\$125k - \$175k) & 0.489 & 0.14 & 3.562 & 0.488 & 0.14 & 3.557 & 0.599 & 0.14 & 4.178 & 0.173 & 0.18 & 0.971 & 0.119 & 0.18 & 0.665 \\
\hline HH Inc. (> \$175k) & 0.477 & 0.14 & 3.298 & 0.464 & 0.14 & 3.203 & 0.592 & 0.15 & 3.872 & 0.237 & 0.19 & 1.26 & 0.167 & 0.19 & 0.885 \\
\hline HH Income (Undisclosed) & -0.1 & 0.13 & -0.82 & -0.1 & 0.13 & -0.76 & -0.03 & 0.13 & -0.2 & -0.36 & 0.17 & -2.08 & -0.4 & 0.18 & -2.27 \\
\hline Gender (Male) & 0.111 & 0.07 & 1.692 & 0.125 & 0.07 & 1.905 & 0.12 & 0.07 & 1.828 & 0.136 & 0.08 & 1.728 & 0.108 & 0.08 & 1.36 \\
\hline Gender (other) & 0.86 & 0.46 & 1.86 & 0.756 & 0.46 & 1.635 & 0.692 & 0.46 & 1.504 & 0.138 & 0.64 & 0.217 & 0.102 & 0.63 & 0.162 \\
\hline Physically Disabled & 0.151 & 0.11 & 1.367 & 0.132 & 0.11 & 1.195 & 0.13 & 0.11 & 1.181 & -0.01 & 0.15 & -0.07 & -0.04 & 0.15 & -0.28 \\
\hline \# of Driver Collisions & -0.11 & 0.06 & -1.75 & -0.07 & 0.06 & -1.2 & -0.04 & 0.06 & -0.66 & -0.06 & 0.08 & -0.82 & -0.08 & 0.08 & -1.06 \\
\hline \# of Passenger Collisions & 0.298 & 0.07 & 4.227 & 0.308 & 0.07 & 4.373 & 0.283 & 0.07 & 3.991 & 0.307 & 0.09 & 3.567 & 0.291 & 0.09 & 3.373 \\
\hline Household Size & 0.131 & 0.07 & 1.767 & 0.201 & 0.07 & 2.683 & 0.117 & 0.08 & 1.477 & 0.131 & 0.1 & 1.346 & 0.117 & 0.1 & 1.196 \\
\hline Household under 15 & -0.05 & 0.09 & -0.63 & -0.06 & 0.09 & -0.69 & 0.001 & 0.09 & 0.013 & 0.009 & 0.1 & 0.091 & 0.013 & 0.1 & 0.129 \\
\hline Job Density (10k radius) & - & - & - & 0.295 & 0.05 & 6.365 & 0.25 & 0.05 & 5.178 & 0.075 & 0.06 & 1.224 & 0.057 & 0.06 & 0.92 \\
\hline Vehicle Cost (over $\$ 30 k$ ) & - & - & - & - & - & - & -0 & 0.07 & -0.03 & -0.04 & 0.09 & -0.51 & -0.06 & 0.09 & -0.74 \\
\hline Vehicles per Adult & - & - & - & - & - & - & -0.51 & 0.15 & -3.34 & -0.53 & 0.22 & -2.44 & -0.62 & 0.22 & -2.83 \\
\hline Commute (GO Train) & - & - & - & - & - & - & - & - & - & 0.509 & 0.18 & 2.876 & 0.545 & 0.18 & 3.049 \\
\hline Commute (Public Transit) & - & - & - & - & - & - & - & - & - & 0.377 & 0.13 & 2.955 & 0.379 & 0.13 & 2.941 \\
\hline Commute (Bike/Walk) & - & - & - & - & - & - & - & - & - & 0.505 & 0.18 & 2.766 & 0.481 & 0.19 & 2.592 \\
\hline Typical Commute Time & - & - & - & - & - & - & - & - & - & 0.042 & 0.06 & 0.731 & 0.033 & 0.06 & 0.586 \\
\hline Travelled Yesterday & - & - & - & - & - & - & - & - & - & 0.241 & 0.13 & 1.846 & 0.185 & 0.13 & 1.405 \\
\hline Uber (have used) & - & - & - & - & - & - & - & - & - & 1.123 & 0.12 & 9.759 & 1.118 & 0.12 & 9.663 \\
\hline Uber(1-3 per month) & - & - & - & - & - & - & - & - & - & 1.353 & 0.13 & 10.22 & 1.336 & 0.13 & 10.06 \\
\hline Uber (1 per week) & - & - & - & - & - & - & - & - & - & 1.311 & 0.2 & 6.67 & 1.293 & 0.2 & 6.528 \\
\hline Uber (2+ per week) & - & - & - & - & - & - & - & - & - & 1.67 & 0.24 & 6.818 & 1.658 & 0.25 & 6.761 \\
\hline Sense of Freedom & - & - & - & - & - & - & - & - & - & - & - & - & -0.08 & 0.13 & -0.67 \\
\hline Sense of Control & - & - & - & - & - & - & - & - & - & - & - & - & 0.149 & 0.1 & 1.464 \\
\hline Not aware of Google Car & - & - & - & - & - & - & - & - & - & - & - & - & -0.31 & 0.08 & -3.8 \\
\hline Own a Smartphone & - & - & - & - & - & - & - & - & - & - & - & - & 0.661 & 0.17 & 3.799 \\
\hline Residual Deviance: & 8862 & & & 8821 & & & 8810 & & & 6055 & & & 6022 & & \\
\hline AIC: & 8900 & & & 8861 & & & 8854 & & & 6117 & & & 6092 & & \\
\hline Sample Size & 3184 & & & 3184 & & & 3184 & & & 2144 & & & 2144 & & \\
\hline
\end{tabular}


Table 5: SAV Frequency of Use at $\$ 1.00$ per $\mathrm{km}$

\begin{tabular}{|c|c|c|c|c|c|c|c|c|c|c|c|c|c|c|c|}
\hline SAV Monthly \$1.00 & (1) & & & (2) & & & (3) & & & (4) & & & (5) & & \\
\hline & Coef & Std.E & $t$-stat & Value & Std.E & $t$-stat & Value & Std.E & $t$-stat & Value & Std.E & $t$-stat & Value & Std.E & t-stat \\
\hline Age (35-54) & -0.58 & 0.08 & -7.17 & -0.59 & 0.08 & -7.33 & -0.61 & 0.08 & -7.56 & -0.23 & 0.09 & -2.45 & -0.2 & 0.1 & -2.11 \\
\hline Age (55-75) & -0.97 & 0.1 & -9.98 & -0.97 & 0.1 & -9.91 & -0.98 & 0.1 & -9.98 & -0.18 & 0.14 & -1.27 & -0.11 & 0.14 & -0.8 \\
\hline HH Inc. (\$40k ><x < \$60k) & 0.154 & 0.13 & 1.151 & 0.161 & 0.13 & 1.203 & 0.187 & 0.13 & 1.384 & 0.049 & 0.17 & 0.283 & 0.024 & 0.17 & 0.141 \\
\hline HH Inc. (\$60k < x < \$100k) & 0.264 & 0.12 & 2.198 & 0.259 & 0.12 & 2.15 & 0.304 & 0.12 & 2.46 & 0.06 & 0.16 & 0.38 & 0.031 & 0.16 & 0.198 \\
\hline HH Inc. $(\$ 100 k<x<\$ 125 k)$ & 0.276 & 0.14 & 1.952 & 0.277 & 0.14 & 1.956 & 0.323 & 0.15 & 2.188 & -0.08 & 0.18 & -0.43 & -0.12 & 0.18 & -0.65 \\
\hline HH Inc. (\$125k - \$175k) & 0.318 & 0.14 & 2.222 & 0.312 & 0.14 & 2.176 & 0.339 & 0.15 & 2.264 & -0.05 & 0.19 & -0.26 & -0.08 & 0.19 & -0.44 \\
\hline HH Inc. (> \$175k) & 0.233 & 0.15 & 1.547 & 0.216 & 0.15 & 1.432 & 0.245 & 0.16 & 1.532 & -0.13 & 0.2 & -0.66 & -0.17 & 0.2 & -0.89 \\
\hline HH Income (Undisclosed) & -0.24 & 0.13 & -1.81 & -0.24 & 0.14 & -1.8 & -0.21 & 0.14 & -1.54 & -0.48 & 0.18 & -2.62 & -0.51 & 0.18 & -2.8 \\
\hline Gender (Male) & 0.041 & 0.07 & 0.604 & 0.053 & 0.07 & 0.769 & 0.044 & 0.07 & 0.637 & 0.064 & 0.08 & 0.779 & 0.03 & 0.08 & 0.361 \\
\hline Gender (other) & 1.122 & 0.45 & 2.517 & 1.018 & 0.45 & 2.278 & 0.997 & 0.44 & 2.246 & 0.276 & 0.61 & 0.454 & 0.197 & 0.61 & 0.325 \\
\hline Physically Disabled & 0.276 & 0.12 & 2.368 & 0.267 & 0.12 & 2.301 & 0.269 & 0.12 & 2.31 & 0.334 & 0.16 & 2.11 & 0.329 & 0.16 & 2.064 \\
\hline \# of Driver Collisions & -0.14 & 0.07 & -2.15 & -0.11 & 0.07 & -1.65 & -0.08 & 0.07 & -1.24 & -0.07 & 0.08 & -0.92 & -0.08 & 0.08 & -0.96 \\
\hline \# of Passenger Collisions & 0.178 & 0.07 & 2.413 & 0.19 & 0.07 & 2.575 & 0.166 & 0.07 & 2.232 & 0.146 & 0.09 & 1.617 & 0.132 & 0.09 & 1.453 \\
\hline Household Size & 0.025 & 0.08 & 0.323 & 0.094 & 0.08 & 1.206 & 0.008 & 0.08 & 0.1 & 0.045 & 0.1 & 0.436 & 0.04 & 0.1 & 0.392 \\
\hline Household under 15 & 0.098 & 0.09 & 1.091 & 0.091 & 0.09 & 1.013 & 0.139 & 0.09 & 1.511 & 0.103 & 0.11 & 0.965 & 0.096 & 0.11 & 0.895 \\
\hline Job Density (10k radius) & - & - & - & 0.296 & 0.05 & 6.063 & 0.249 & 0.05 & 4.893 & 0.063 & 0.07 & 0.961 & 0.05 & 0.07 & 0.766 \\
\hline Vehicle Cost (over \$30k) & - & - & - & - & - & - & 0.209 & 0.08 & 2.739 & 0.153 & 0.09 & 1.688 & 0.139 & 0.09 & 1.529 \\
\hline Vehicles per Adult & - & - & - & - & - & - & -0.51 & 0.16 & -3.24 & -0.59 & 0.23 & -2.6 & -0.62 & 0.23 & -2.71 \\
\hline Commute (GO Train) & - & - & - & - & - & - & - & - & - & 0.689 & 0.18 & 3.806 & 0.706 & 0.18 & 3.86 \\
\hline Commute (Public Transit) & - & - & - & - & - & - & - & - & - & 0.463 & 0.13 & 3.486 & 0.446 & 0.13 & 3.329 \\
\hline Commute (Bike/Walk) & - & - & - & - & - & - & - & - & - & 0.209 & 0.19 & 1.1 & 0.145 & 0.19 & 0.75 \\
\hline Typical Commute Time & - & - & - & - & - & - & - & - & - & -0.15 & 0.06 & -2.49 & -0.16 & 0.06 & -2.6 \\
\hline Travelled Yesterday & - & - & - & - & - & - & - & - & - & 0.169 & 0.14 & 1.25 & 0.158 & 0.14 & 1.161 \\
\hline Uber (have used) & - & - & - & - & - & - & - & - & - & 0.965 & 0.12 & 8.116 & 0.966 & 0.12 & 8.074 \\
\hline Uber(1-3 per mth) & - & - & - & - & - & - & - & - & - & 1.401 & 0.14 & 10.22 & 1.393 & 0.14 & 10.14 \\
\hline Uber (1 per week) & - & - & - & - & - & - & - & - & - & 1.796 & 0.2 & 8.956 & 1.751 & 0.2 & 8.673 \\
\hline Uber (2+ per week) & - & - & - & - & - & - & - & - & - & 2.387 & 0.26 & 9.068 & 2.345 & 0.27 & 8.84 \\
\hline Sense of Freedom & - & - & - & - & - & - & - & - & - & - & - & - & -0.31 & 0.13 & -2.38 \\
\hline Sense of Control & - & - & - & - & - & - & - & - & - & - & - & - & 0.179 & 0.11 & 1.689 \\
\hline Not aware of Google Car & - & - & - & - & - & - & - & - & - & - & - & - & -0.22 & 0.09 & -2.61 \\
\hline Own a Smartphone & - & - & - & - & - & - & - & - & - & - & - & - & 0.329 & 0.18 & 1.791 \\
\hline Residual Deviance: & 7420 & & & 7383 & & & 7368 & & & 5114 & & & 5097 & & \\
\hline AIC: & 7458 & & & 7423 & & & 7412 & & & 5176 & & & 5167 & & \\
\hline Sample Size & 3184 & & & 3184 & & & 3184 & & & 2144 & & & 2144 & & \\
\hline
\end{tabular}


Table 6: SAV Frequency of Use at $\$ 1.50$ per $\mathrm{km}$

\begin{tabular}{|c|c|c|c|c|c|c|c|c|c|c|c|c|c|c|c|}
\hline SAV Monthly \$1.50 & (1) & & & (2) & & & (3) & & & (4) & & & (5) & & \\
\hline & Coef & Std.E & t-stat & Coef & Std.E & t-stat & Coef & Std.E & $t$-stat & Coef & Std.E & $t$-stat & Coef & Std.E & $t$-stat \\
\hline Age (35-54) & -0.64 & 0.09 & -7.42 & -0.66 & 0.09 & -7.55 & -0.68 & 0.09 & -7.73 & -0.28 & 0.1 & -2.73 & -0.26 & 0.1 & -2.53 \\
\hline Age (55-75) & -0.9 & 0.11 & -8.42 & -0.9 & 0.11 & -8.41 & -0.9 & 0.11 & -8.46 & -0.18 & 0.16 & -1.14 & -0.12 & 0.16 & -0.77 \\
\hline HH Inc. $(\$ 40 k><x<\$ 60 k)$ & 0.179 & 0.14 & 1.235 & 0.187 & 0.14 & 1.289 & 0.207 & 0.15 & 1.414 & 0.117 & 0.19 & 0.627 & 0.106 & 0.19 & 0.562 \\
\hline HH Inc. (\$60k < x $<\$ 100 k)$ & 0.243 & 0.13 & 1.86 & 0.242 & 0.13 & 1.845 & 0.273 & 0.13 & 2.027 & 0.105 & 0.17 & 0.604 & 0.076 & 0.17 & 0.436 \\
\hline HH Inc. $(\$ 100 k<x<\$ 125 k)$ & 0.295 & 0.15 & 1.907 & 0.295 & 0.16 & 1.901 & 0.317 & 0.16 & 1.96 & 0.033 & 0.2 & 0.163 & 0.008 & 0.2 & 0.037 \\
\hline HH Inc. (\$125k - \$175k) & 0.316 & 0.15 & 2.047 & 0.31 & 0.15 & 2.005 & 0.316 & 0.16 & 1.944 & 0.058 & 0.2 & 0.288 & 0.037 & 0.2 & 0.18 \\
\hline HH Inc. (> \$175k) & 0.213 & 0.16 & 1.295 & 0.194 & 0.17 & 1.172 & 0.194 & 0.17 & 1.11 & -0.1 & 0.21 & -0.47 & -0.14 & 0.22 & -0.64 \\
\hline HH Income (Undisclosed) & -0.28 & 0.15 & -1.88 & -0.28 & 0.15 & -1.86 & -0.26 & 0.15 & -1.7 & -0.44 & 0.2 & -2.17 & -0.47 & 0.21 & -2.28 \\
\hline Gender (Male) & 0.104 & 0.07 & 1.381 & 0.113 & 0.08 & 1.507 & 0.105 & 0.08 & 1.388 & 0.032 & 0.09 & 0.353 & 0.01 & 0.09 & 0.11 \\
\hline Gender (other) & 0.91 & 0.48 & 1.894 & 0.782 & 0.49 & 1.613 & 0.784 & 0.48 & 1.617 & 0.091 & 0.67 & 0.136 & 0.051 & 0.67 & 0.077 \\
\hline Physically Disabled & 0.503 & 0.12 & 4.084 & 0.493 & 0.12 & 4 & 0.5 & 0.12 & 4.05 & 0.666 & 0.17 & 4.007 & 0.668 & 0.17 & 3.997 \\
\hline \# of Driver Collisions & -0.26 & 0.07 & -3.58 & -0.23 & 0.07 & -3.13 & -0.21 & 0.07 & -2.84 & -0.17 & 0.09 & -1.84 & -0.16 & 0.09 & -1.72 \\
\hline \# of Passenger Collisions & 0.162 & 0.08 & 2.014 & 0.173 & 0.08 & 2.145 & 0.156 & 0.08 & 1.926 & 0.133 & 0.1 & 1.348 & 0.113 & 0.1 & 1.139 \\
\hline Household Size & -0.06 & 0.08 & -0.71 & 0.007 & 0.09 & 0.081 & -0.06 & 0.09 & -0.69 & -0.09 & 0.11 & -0.78 & -0.09 & 0.11 & -0.78 \\
\hline Household under 15 & 0.257 & 0.1 & 2.62 & 0.254 & 0.1 & 2.581 & 0.292 & 0.1 & 2.907 & 0.331 & 0.12 & 2.823 & 0.328 & 0.12 & 2.784 \\
\hline Job Density (10k radius) & - & - & - & 0.306 & 0.05 & 5.75 & 0.27 & 0.06 & 4.861 & 0.119 & 0.07 & 1.675 & 0.109 & 0.07 & 1.531 \\
\hline Vehicle Cost (over $\$ 30 k$ ) & - & - & - & - & - & - & 0.219 & 0.08 & 2.616 & 0.166 & 0.1 & 1.684 & 0.155 & 0.1 & 1.564 \\
\hline Vehicles per Adult & - & - & - & - & - & - & -0.41 & 0.17 & -2.36 & -0.52 & 0.25 & -2.11 & -0.52 & 0.25 & -2.1 \\
\hline Commute (GO Train) & - & - & - & - & - & - & - & - & - & 0.753 & 0.19 & 3.933 & 0.73 & 0.19 & 3.773 \\
\hline Commute (Public Transit) & - & - & - & - & - & - & - & - & - & 0.574 & 0.14 & 4.014 & 0.534 & 0.14 & 3.704 \\
\hline Commute (Bike/Walk) & - & - & - & - & - & - & - & - & - & 0.56 & 0.2 & 2.773 & 0.486 & 0.21 & 2.372 \\
\hline Typical Commute Time & - & - & - & - & - & - & - & - & - & -0.15 & 0.06 & -2.39 & -0.16 & 0.06 & -2.44 \\
\hline Travelled Yesterday & - & - & - & - & - & - & - & - & - & 0.326 & 0.15 & 2.17 & 0.328 & 0.15 & 2.172 \\
\hline Uber (have used) & - & - & - & - & - & - & - & - & - & 0.663 & 0.13 & 5.17 & 0.648 & 0.13 & 5.032 \\
\hline Uber(1-3 per mth) & - & - & - & - & - & - & - & - & - & 1.217 & 0.14 & 8.588 & 1.193 & 0.14 & 8.408 \\
\hline Uber (1 per week) & - & - & - & - & - & - & - & - & - & 2.045 & 0.21 & 9.971 & 1.999 & 0.21 & 9.667 \\
\hline Uber (2+ per week) & - & - & - & - & - & - & - & - & - & 2.205 & 0.27 & 8.229 & 2.141 & 0.27 & 7.955 \\
\hline Sense of Freedom & - & - & - & - & - & - & - & - & - & - & - & - & -0.29 & 0.14 & -2.13 \\
\hline Sense of Control & - & - & - & - & - & - & - & - & - & - & - & - & 0.017 & 0.11 & 0.153 \\
\hline Not aware of Google Car & - & - & - & - & - & - & - & - & - & - & - & - & -0.17 & 0.09 & -1.79 \\
\hline Own a Smartphone & - & - & - & - & - & - & - & - & - & - & - & - & 0.437 & 0.22 & 2.001 \\
\hline Residual Deviance: & 5997 & & & 5964 & & & 5953 & & & 4175 & & & 4163 & & \\
\hline AIC: & 6035 & & & 6004 & & & 5997 & & & 4237 & & & 4233 & & \\
\hline Sample Size & 3184 & & & 3184 & & & 3184 & & & 2144 & & & 2144 & & \\
\hline
\end{tabular}




\section{Chapter 6: Discussion}

\subsection{Private vs. Shared Autonomous Vehicles}

Results indicate that while a number of respondents are interested in autonomous vehicles regardless of the ownership model, individual preferences for one form of ownership over another do clearly exist. Table \#7 highlights the distribution of responses to these two survey questions:

Table 7: WTP for Level 5 and Frequency of using SAVs at $\$ 0.50$ per $\mathrm{km}$

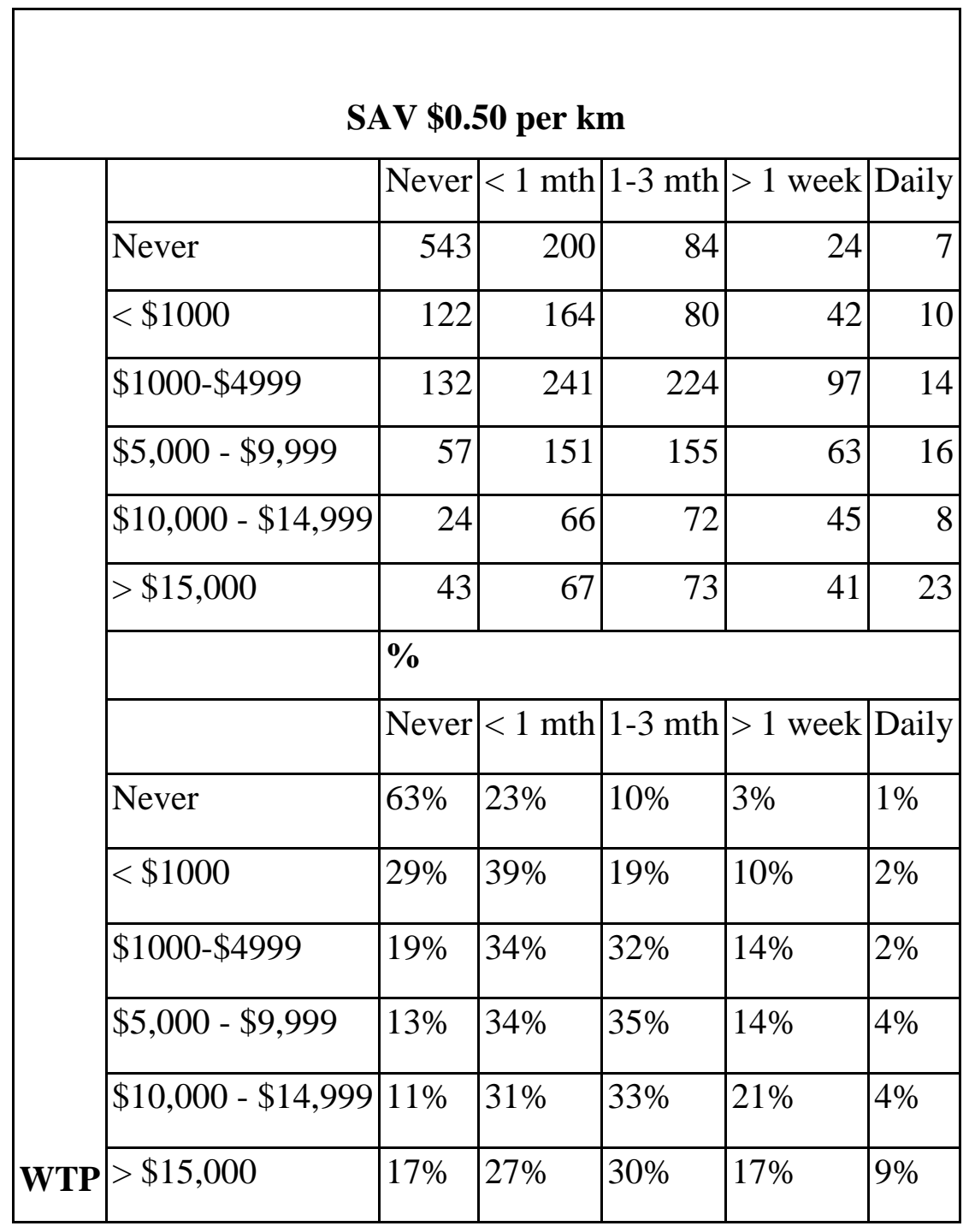


$37 \%$ of respondents who expressed no interest in purchasing a private AV would utilize an SAV service at $\$ 0.50$ per $\mathrm{km}$. Conversely, $41 \%$ of respondents who would never use a shared AV at that price point indicated that they would pay a premium for a personal AV. These results indicate that the two ownership models may exist simultaneously to serve their respective markets. Given that many respondents expressed interest in both personal and shared AVs, cost and quality of service will likely determine the respective market shares of the two ownership models. It is also conceivable that there will be individuals who use both ownership models once they are made available. However, it is important to note that only a minority of respondents expressed interest in using a SAV at a regular frequency ( $>1$ per week). Even at the lowest price point of $\$ 0.50$ per km, only $14 \%$ of respondents would use a SAV on a regular basis. Many respondents currently view SAVs as a substitute for current taxi/Uber usage rather than a viable commuting alternative but those preferences could shift as individuals become more familiar with the technology.

The results indicate that several key differences exist between respondents interested in PAVs and SAVs. Middle income (\$60-\$100k) and high income (> $\$ 175 \mathrm{k})$ households respondents have paid over a $\$ 30 \mathrm{k}$ for a vehicle, and live in an area with a higher density of jobs displayed a preference for personal AVs. Unsurprisingly, affluent households are more interested in personal AVs but the additional WTP of middle income households defies easy explanation. Earlier iterations of the model displayed a consistently positive relationship between household income and WTP for Level 5, but this relationship loses most of its explanatory power once Commuting/Travel Behaviour is included in model (3). This observation likely indicates that household income is being reflected in the commute mode preferences and household location choices that are being made by respondents.

Conversely, respondents who have been in a higher number of passenger collisions, commute using public transit, or commute by walking/cycling displayed more interest in shared AVs. Individuals who commute using GO transit, have used Uber, and own a smartphone were interested in both ownership models. In addition, never having heard of the Google car was a strong predictor of disinterest in $\mathrm{AVs}$, regardless of the ownership model. It is interesting to note that respondents who use Uber 1-3 times per month have a higher WTP when compared to frequent (2+ per week) users, an observation indicating that Uber use and WTP for a PAV do not 
possess a linear relationship. The diminishing interest in PAVs as Uber use increases is likely a reflection of frequent Uber users being less reliant upon (or not having) a personal vehicle.

\subsection{Trip Purpose}

The larger set of results detailed in Tables \#3 and \#4 provide insight into how AVs could affect public transit ridership. Current public transit users displayed no discernible interest in paying an additional premium for a personal AV but did express interest in using a shared AV at all three price points. This result could have important implications for the future viability of public transit. Public transit user disinterest in private AVs is a positive sign that this form of ownership will not erode transit ridership. Given that the majority of public transit users are located in Toronto where they have access to a rapid transit network, it is perhaps not surprising that they are less interested in PAVs when compared to respondents living in more sparsely populated areas. However, public transit users did express interest in using shared AVs and this could potentially complement or detract from existing public transit usage. Conversely, GO transit users expressed interest in both ownership models and the potential for erosion of ridership if a private/shared AVs can offer the same benefits that are associated with using commuter rail (namely, not having to drive in rush hour traffic and being able to relax or commuting).

To further explore how SAVs may influence travel behavior, different user groups were considered to understand if SAVs would be used for commuting or discretionary travel purposes. An interaction term was included to capture the joint effect of commuting to work/school using an automobile and having travelled in an automobile yesterday on interest in SAVs. This approach was also taken for commuting using public transit to ascertain if any differences exist. The model specification indicates that no significant differences exists between consumers' willingness to use for SAVs for primary commute mode or discretionary travel use. 


\subsection{Implications of Research}

This research has revealed interesting insights into how consumers may use and adopt private autonomous vehicles and shared autonomous vehicles. Using a statistical approach allows us to identify the conditions and characteristics of potential users that are most likely to influence adoption. This is significant for public policy as it is necessary to understand future travel behavior changes and how autonomous vehicles will integrate into the existing transportation network. Moreover, public policy makers may be able to help encourage or discourage a future from happening. These models are useful for predicting future mode shares and travel demand under different pricing thresholds for PAVs and SAVs. Our results present unique findings, increasing the clarity surrounding how autonomous vehicles will affect travel behavior changes. Familiarity with the Google Car or using technology was shown in other studies to be an indicator of willingness to adopt new technologies (Bansal, Kockelman, \& Singh, 2016; Zmud, Sener \& Wagner, 2016; Lavieri et al., 2017). This is in line with our findings that knowing about the Google Car or owning a smartphone suggest future use of an SAV or PAV. Our findings also suggest that younger respondents are more willing to pay for a PAV and use an SAV; this adds information to the set of literature that disagrees with whether age is a statistically significant factor influencing use of AVs. Our findings are unique in that public transportation users were examined; the results suggest that GO Train users are likely going to be users of this technology. Policy makers will be able to make more efficient recommendations and actions based on this research. 


\section{Chapter 7: Conclusion}

Understanding the conditions under which consumers will adopt and use private autonomous and shared autonomous vehicles will allow policymakers to advance sustainable transportation goals. Visions of how autonomous vehicles may unfold are divergent in that they may either promote or harm the public interest. Given the limited knowledge coupled with the public's hype and anxiety, a significant need exists for this research. These results provide a preliminary indication of the effect of demographic characteristics, individual preferences, travel characteristics, and built-environment variables on respondent's willingness to pay for private autonomous vehicles (PAVs) and frequency of use for shared autonomous vehicles (SAVs) under different pricing thresholds. The results of this research are inconsistent with the view that autonomous vehicles may present an opportunity for a reduction in personal vehicle ownership. Our findings also indicate that travel behavior changes will occur with the proliferation of autonomous vehicles. Public transportation users, such as GO train users, may be some of the first adopters and users of this new technology. Future studies could continue to explore if the markets for PAVs and SAVs are significantly different from each other. Knowledge of which conditions will influence autonomous vehicle use is of great interest to shaping policies and transportation systems. This work will help guide policymakers and communities in estimating future adoption of automated vehicle technology. Policymakers and transportations planners can help shape our cities into healthier places to live by understanding the conditions under which new technology may change our travel behaviours and landscape patterns. 
Appendix: Survey Instrument

\section{Automated Vehicles in the Greater Toronto-Hamilton Area: 2016 Consumer Survey}

Matthias Sweet, Assistant Professor

Ryerson University School of Urban and Regional Planning matthiassweet@ryerson.ca

416-979-5000 ext. 6774

Kailey Laidlaw, Graduate Student

Ryerson University School of Urban and Regional Planning kailey.laidlaw@ryerson.ca 


\section{TABLE OF CONTENTS}

Background Information .................................................................................. 40

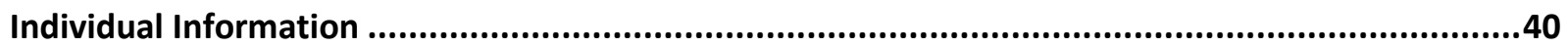

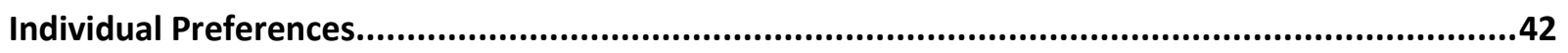

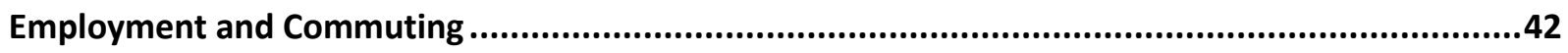

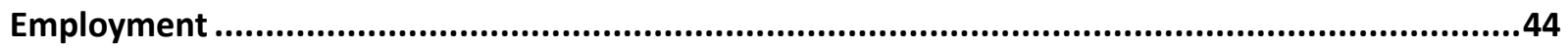

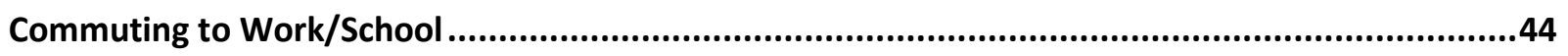

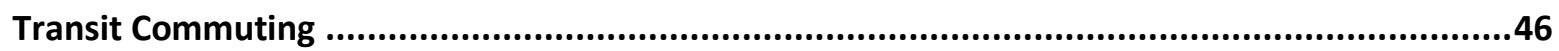

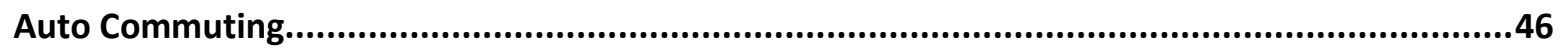

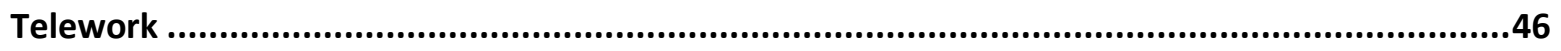

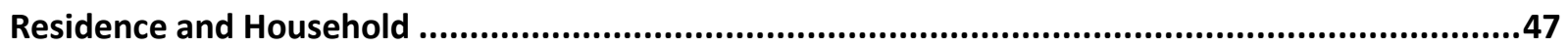

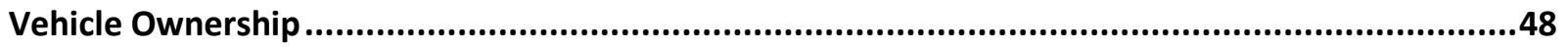

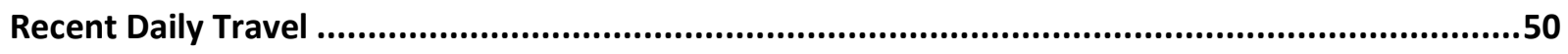

Travel Preferences and Choices ......................................................................... 52

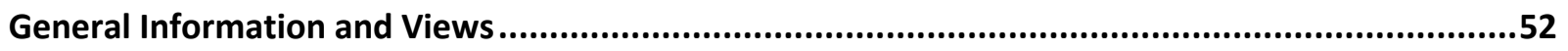

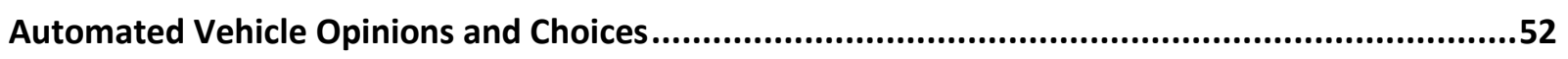

Prospective Travel and Location Choices...............................................................................55

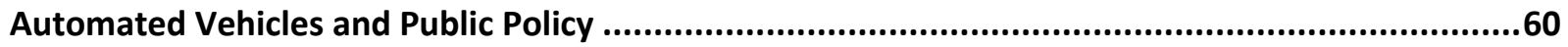


Survey and Consent Forms

\section{[SCREEN \#1 UPON RECEIVING SOLICITATION EMAIL AND SELECTING LINK INDICATING INTEREST IN PARTICIPATING IN A GENERIC SURVEY]}

Professor Matthias Sweet, and graduate student, Kailey Laidlaw, of the School of Urban and Regional Planning, are conducting a survey on residents' perceptions of automated vehicles (driverless cars) and what this new technology may mean for how our cities function. This travel survey is jointly funded by Metrolinx and the City of Toronto and it informs ongoing transportation planning efforts.

\section{[SCREEN 2]}

What will happen during the study?

You will be asked a series of questions which are either multiple choice or with a fixed numerical answer. Questions cover the following broad topics:

- $\quad$ commuting experiences and auto ownership,

- characteristics of your household,

- $\quad$ attitudes towards travel,

- $\quad$ your living arrangements, and

- $\quad$ attitudes towards automated vehicles.

\section{[SCREEN 3]}

This survey will take approximately 20 minutes. We hope that you answer all questions, as this survey plays a key role in preparing the Greater Toronto-Hamilton Area for automated vehicles. Upon finishing the survey, you will be given the option of contacting us should you be interested in participating in possible future in-person focus groups on the topic of automated vehicles. The survey is administered by Research Now (www.researchnow.com) who does not have legal rights to retain this data; all data processing or storage will occur in Canada.

\section{[SCREEN 4]}

Are there any risks to doing this study?

It is not likely that there will be any harm or discomforts from participating in this survey. The survey will not ask you to provide personal identifiers (e.g. your name, your social insurance number) and we do not have a master list of potential survey participants. However, the survey will ask you to respond to several demographic questions, which taken together, may be a unique combination of answers. Nevertheless, as the study team has no master list of potential survey participants and their detailed characteristics, we cannot identify you even if your combination of survey answers is unique.

[SCREEN 5] 
Are there any benefits to doing this study?

This research will provide valuable information for transportation planning researchers to better understand how automated vehicles are likely to influence society.

This research will inform the City of Toronto and Metrolinx, the project funders, in better anticipating and preparing for automated vehicles in the region.

\section{[SCREEN 6]}

Who will know what I said or did in the study?

Questions we are asking you do not contain uniquely-identifiable information and we are not collecting computer IP addresses, so we cannot track you individually in the dataset and this survey is confidential. The survey results will be managed by the Principal Investigator, Professor Matthias Sweet, and his research team and the data will only be available to the study team and the funders. Data will be stored indefinitely on secured computers in Professor Sweet's research lab (www.transformlab.ryerson.ca).

\section{[SCREEN 7]}

How do I find out what was learned in this study?

For updates and information about the study findings, please visit (www.transformlab.ryerson.ca/projects/). Findings are expected to be made public in the Summer of 2017.

Questions about the Study:

If you have questions or need more information about the study itself, please contact the Principal Investigator, Matthias Sweet of Ryerson University, at:

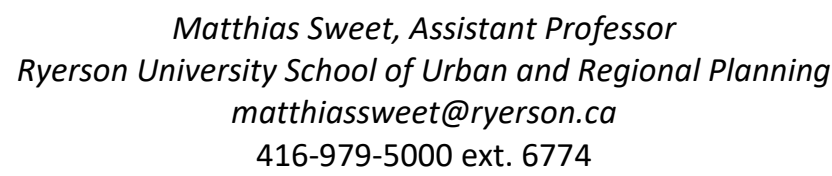

\section{[SCREEN 8]}

This study has been reviewed by the Ryerson University Research Ethics Board and received ethics clearance. If you have any questions about your rights or treatment as a research participant in this study, please contact the Ryerson University Research Ethics Board at rebchair@ryerson.ca (416) 979-5042. 


\section{[SCREEN 9]}

\section{CONSENT}

- I have read the information presented above about a study being conducted by Ryerson University's School of Urban and Regional Planning and funded by Metrolinx and the City of Toronto.

- I have had the opportunity to ask questions about my involvement in this study and to receive additional details I requested.

- I understand that if I agree to participate in this study, I may withdraw from the study at any time by exiting the online survey. Participation in this research is completely voluntary.

However, because the survey is anonymous, once you click the submit button at the end of the survey the researchers will not be able to determine which survey answers belong to you so your information cannot be withdrawn after that point. By consenting to participate you are not waiving any of your legal rights as a research participant.

- By selecting the survey link below, I agree to participate in the study.

- If you are interested in participating, the following link will take you to the survey: [SURVEY LINK] 


\section{Background Information}

\section{Individual Information}

1. My age is (in years):

[RN: termination point: only include 18-75]

2. My current place of residence is:

The first three digits of your postal code are (i.e. A\#A - no spaces in between) [RN: The FSA question is asked alone and in isolation without the other two below. Upon entering the three digits of the FSA, two actions are possible:

a. If an FSA is in Table Q (also attached in excel), then the participant is prompted with either:]

Your response indicates that you reside in [from m:m table]

\section{Or}

Your response indicates that you reside in either Or

Your response indicates that you reside in either or or

c. [Then the respondent is prompted with:] Is this true? Yes No

d. [If they select no, they are terminated.

e. If they respond "yes", and only one region is identified in the table (Q), then the respondent is done with the location questions and is eligible based on the locational requirement. >NON-TERMINATION LOGIC.

f. If they respond "yes," and two or three regions are identified in table (Q), then the 2 or 3 regions are highlighted and clickable and the participant is further prompted with:] Please select in which region/city you reside from above.

g. [Then the names of the regions (the underlined component above) are highlighted and additional text reads below]

Please select the city or region in which you reside.

ii. [Upon selecting the city/region in which they reside, the respondent is done with the location questions and is eligible for the survey based on locational requirements > NON-TERMINATION LOGIC.] 
3. I self-identify as:

Female

Male

Other

4. I currently hold a driver's license

Yes

No

5. The number of people in my household who hold a license, including me:

[fill in, numerical 0:99]

6. I regularly carry a smartphone (e.g. an iPhone, Blackberry, Android, etc.)

Yes

No

Unsure

7. I have a physical disability which influences my ability to go places.

* Strongly disagree *Disagree * Neither disagree or agree * Agree

*Strongly agree

8. The highest level of education I have attained is:

Did not complete high school

High school Diploma or Equivalent

Registered Apprenticeship or other trades certificate or diploma

College, CEGEP or other non-university certificate or diploma

Bachelor's Degree

Degree in medicine, dentistry, veterinary medicine or optometry

Graduate Degree (e.g. Master's or Doctoral Degree) 


\section{Individual Preferences}

Please indicate the degree to which you agree or disagree with the following statements.

9. I always plan things in advance.

* Strongly Agree * Agree * Neither agree or disagree *Disagree * Strongly Disagree

10. I'm very protective of my personal space.

* Strongly Agree * Agree * Neither agree or disagree *Disagree * Strongly Disagree

11. I like to be in control.

* Strongly Agree * Agree * Neither agree or disagree * Disagree * Strongly Disagree

12. If I'm traveling to a meeting, I allow extra time in case my trip is delayed

* Strongly Agree * Agree * Neither agree or disagree *Disagree * Strongly Disagree

13. Driving a car gives me a sense of control

* Strongly Agree * Agree * Neither agree or disagree *Disagree * Strongly Disagree

14. Having a car gives me a great sense of freedom

* Strongly Agree * Agree * Neither agree or disagree *Disagree * Strongly Disagree

15. I'm often one of the first people to try out a new product

* Strongly Agree * Agree * Neither agree or disagree *Disagree * Strongly Disagree

16. I like to work hard and play hard

* Strongly Agree * Agree * Neither agree or disagree *Disagree * Strongly Disagree

17. I live a hectic life*

*Strongly Agree * Agree * Neither agree or disagree *Disagree * Strongly Disagree

\section{Employment and Commuting}

[NOTE TO RESEARCH NOW: SEVERAL SUBSEQUENT QUESTIONS PIVOT OFF OF THE NEXT TWO]

18. Currently, I am:

Not a student

A part time student

A full time student 
19. Currently, I am:

Employed full time

Employed part time

Work at home full time

Work at home part time

Unemployed

Not in the labour force

Retired

Other

[Note, for survey programming, the following terms above need to be defined when the participant hovers over the terms: is it possible for this be defined when participant hovers over the dot not just the category?]

Full time: This category includes employed persons who usually worked 30 hours or more per week, at their main or only job.

Part time: This category includes employed persons who usually worked less than 30 hours per week, at their main or only job.

Unemployed: Were without work and had looked for work within the past four weeks

Not in the labour force: Unavailable for work or unable to work. It also includes persons who were without work and who had neither actively looked for work in the past four weeks.]

19a. Typically, I work and/or study hours per week. [To be asked of those who work or are a student in Q19]
a. less than 10 hours per week
b. 10-19 hours per week
c. 20-29 hours per week
d. 30-39 hours per week
e. 40-60 hours per week
f. 60 or more hours per week

[Research Now: at this point, we need to categorize the survey participants into the following bins based on Q18 and Q19 which are relevant for future questions:

Non-workers (Those who answered \{ "unemployed" "not in the labour force" or "other" or "retired" $\}$ and "not a student" based on the previous three questions.)

Non-commuters: those who did one of the following:

Answered "employed at home full-time" or

Answered "employed at home part-time."

Dominant Worker Commuters (Those who meet any of the following criteria): 
Selected "employed full-time"

Selected "employed part-time" and ["A part-time student" or "non-student"\}

Dominant Student Commuters: those who meet any of the following criteria):

Selected "student full-time"

Selected "a part-time student," not "employed full-time," and not "employed parttime." ]

[following questions in this sub-section are only asked if "employed full-time" or "employed part-time" or "Work at home full time" or "Work at home part time" are selected in Q18]

\section{Employment}

[THE FOLLOWING CATEGORIES HAVE DESCRIPTIONS WHICH APPEAR WHEN YOU PUT THE CURSOR ON THE TEXT. THE DESCRIPTIONS ARE NOTED BELOW.]

20. My occupation is best characterized as[1]:

General Office/Clerical

Manufacturing / Construction / Trades

Professional / Management / Technical

Sales and Service

Prefer not to answer

[Definitions for Research Now for purposes of programming cursor hover definitions:

General Office/Clerical. Persons who work in an office environment but do not have a specialized post-secondary education and are not managers.

Manufacturing/Construction/Trades. Jobs outside of the office which often require physical work.

Professional/Technical/Management. Jobs needing a specialized post-secondary education or management responsibility.

Sales and Service. People involved in the selling of goods or services at either the wholesale or retail level. ]

[FOR THE PURPOSES OF THE FOLLOWING QUESTIONS, THE FOLLOWING CATEGORIES DICTATE WHICH QUESTIONS ARE ASKED OF DIFFERENT PARTICIPANTS: "NON-WORKER," “DOMINANT COMMUTING WORKER," AND “NON-COMMUTER," AND "DOMINANT STUDENT"]

[Following questions are only asked of DOMINANT COMMUTING WORKERS or DOMINANT STUDENTS.]

\section{Commuting to Work/School}


[RN: THE TEXT "work/school" IS ASSIGNED AS "work" IF DOMINANT COMMUTING WORKER, but "school" if DOMINANT STUDENT. NOTE THE WORK/SCHOOL DISTINCTION SHOULD BE PROGRAMMED BASED ON IDENTITY AS EITHER “DOMINANT COMMUTING WORKER" OR “DOMINANT STUDENT

21. In a typical work/school week, I travel to work/school [ranging from 0 to 7] days per week.

22. On the last work/school day traveled to work/school, my primary mode of transportation was:

Auto driver (alone)

Auto driver (with others)

Auto passenger

Taxi/Uber

Motorcycle

Walk

Bicycle

GO Transit

Public Transit (excluding GO Transit)

Other [enable text write-in]

23. Car parking is available for free where I usually go to work/school

True

False

Unknown

Not applicable

[if DOMINANT COMMUTING WORKER OR DOMINANT STUDENT COMMUTER then]

24. My typical travel time to work/school:

My travel time door-to-door (from my place of residence to my place of work/school) (in min) __ [INPUT FROM 0 TO 999] 


\section{Transit Commuting}

[NEW HEADER, APPLICABLE TO TRANSIT COMMUTERS ONLY]

[APPLIES ONLY TO THOSE WHO INDICATE THAT THEY ARE EMPLOYED OR STUDENTS \& COMMUTE BY PUBLIC TRANSIT IN ]

[IF CATEGORIZED AS DOMINANT WORKERS, THIS SHOULD BE IDENTIFIED AS "work", EVEN IF IDENTIFYING AS PART WORKER/PART STUDENT]

25. Which of the following ways of accessing transit did you use in your commute? Another type of transit (e.g. taking bus service to the GO train) [multi-select] Walking

Cycling

Driving

Someone dropped me off

Taxi/Uber

Other [ENABLE WRITE-IN]

26. Number of transfers when using public transit The number of trip transfers (e.g. switching from train to bus or switching from bus to bus) in my commute to work/school was:

\section{Auto Commuting}

[APPLIES ONLY TO THOSE WHO INDICATE THAT THEY COMMUTE BY CAR in Q26 and indicated "false" in Q23]

27. I typically pay $\$$ [enable 0 to 99.99] per day to park at work/school.

[IF NOT THE VEHICLE DRIVER, select from rows 3,4,8,9 in Q22]

\section{Telework}

[NEW HEADER APPLICABLE TO EMPLOYED PERSONS WHO WORK OUT OF THE HOME FULL OR PART-TIME IN Q18]

Telework is a flexible form of workplace arrangement that allows people to work from home part of the time instead of commuting to an out-of-home work location.

28. The amount of time I currently spend teleworking is:

Not at all

Less than once per month

About 1-3 days per month

1-2 days per week 
3-4 days per week

5 days per week

Occasional partial days

\section{Residence and Household}

29. The dwelling unit in which I reside is best characterized as:

House

Apartment

Townhouse

Unknown

Other [write-in]

30. Number of members in my family living at this location, including me:

31. Number of people under the age of 15 in my household

32. How frequently are you responsible for chauffeuring, dropping off, or accompanying members of your household to places or activities?
*Never
* 1-2 times per week
* 3-6 times per week
* 7 or

more times per week

33. There are a total of [between 0 and 99] employed persons in my household (including me).

34. There are a total of [between 0 and 99] post-secondary students in my household (including me).

[note to Research Now: provide a hover box over "post-secondary" which defines postsecondary as "any education beyond High School, including college, university, technical schools, etc." Also emphasize the font such that individuals know that by highlighting the term they can identify the definition.] 
35. My usual place of work is located in: [ASKED IF INDIVIDUAL IS BOTH EMPLOYED AND WORKED OUT OF HOME FROM Q18 ]

City/Town

The first three digits of your work's postal code are (i.e. A\#A - no spaces in between)

Q35. [RN: Add the following text and a live clickable link which is populated with a link to the url "maps.google.ca"].

36. For help remembering your three-digit work postal code, this [link] to Google Maps is provided for your convenience.

37. My primary place of school is located in: [ASKED IF INDIVIDUAL IS A FULL OR PART-TIME STUDENT IN Q19]

City/Town

The first three digits of your school's postal code is (i.e. A\#A - no spaces in between)

Q37. [RN: Add the following text and a live clickable link which is populated with a link to the url "maps.google.ca"].

For help remembering your three-digit work postal code, this [link] to Google Maps is provided for your convenience.

38. What was the combined income of all members of your household in 2015 ? Please include all wages, dividends, business income, rent, and pensions.

$\$ 0$ to $\$ 14,999$

$\$ 15,000$ to $\$ 39,999$

$\$ 40,000$ to $\$ 59,999$

$\$ 60,000$ to $\$ 99,999$

$\$ 100,000$ to $\$ 124,999$

$\$ 125,000$ to $\$ 175,000$

$\$ 175,000$ and above

Prefer not to answer

I don't know

\section{Vehicle Ownership}


39. I, or a member of my household own(s) a vehicle where I live Yes

No

40. The number of vehicles available for me to use in my household is [0 to 9] [ASKED OF THOSE WHO HAVE ONE OR MORE VEHICLES IN HOUSEHOLD ("Yes") in Q46]

41. Approximately how far did you travel yesterday in a personal vehicle as either an auto passenger or driver? (in kilometers) [ENABLE INTEGER BETWEEN 0 AND 999]

[FOLLOWING SECTION QUESTION ARE ASKED OF AUTO OWNERS BASED ON Q47]

42. My primary vehicle would best be described as Conventional Vehicle (internal combustion engine using gas/diesel) Battery Electric Vehicle (BEV) (e.g. Nissan Leaf or Tesla) Plug-In Hybrid-Electric Vehicle (PHEV) (e.g. Chevy Volt) Hybrid Electric Vehicle (HEV) (e.g. Toyota Prius) Other

43. Type of vehicles I, or members of my household own (enter the number of vehicles in each class; leave blank if zero) [integer 0 to $>5$; 0 should be the default] Small (i.e. Toyota Yaris, Chevrolet Cobalt) Medium (i.e. Pontiac $\mathrm{G} 6$ or Ford Taurus) Large (pick-up truck, minivan, or sports utility vehicle) Other

[IF ONLY ONE VEHICLE IS CHOSEN IN Q53]

44. How much did this vehicle cost you when you or your household purchased it? less than $\$ 15,000$

$\$ 15,000-\$ 30,000$

$\$ 30,000-\$ 45,000$

$\$ 45,000-\$ 60,000$

more than $\$ 60,000$

Move question 53a directly after Q49.

[IF MORE THAN ONE VEHICLE IS CHOSEN IN Q53 ] 
45. How much did you pay for the most recent of these vehicles when you purchased it? less than $\$ 15,000$

$\$ 15,000-\$ 30,000$

$\$ 30,000-\$ 45,000$

$\$ 45,000-\$ 60,000$

more than $\$ 60,000$

\section{[NEXT QUESTION IF RESPONDENT'S HOUSEHOLD DOES HAVE A CAR in Q53]}

46. I am proud of my car.

* Strongly Agree * Agree * Neither agree or disagree *Disagree * Strongly Disagree

47. In my lifetime, I have been in approximately [numerical between 0 and 99] vehicle collisions while driving and [numerical between 0 and 99] vehicle collisions as a passenger.

48. Are you a member of any of the following car share programs? Please select all that apply.

Car sharing is a type of self-service car rental where designated cars are available to be rented by members on an as-needed basis, typically for a short period of time.

I'm not a member of any car share program

I'm a member of ZipCar

I'm a member of car2go

I'm a member of Autoshare

I'm a member of another car share program: [enable write-in]

\section{Recent Daily Travel}

The following section asks you questions about your travel yesterday.

49. Yesterday I took approximately [ALLOW CONTINUOUS INTEGER INPUT from 0 to 99] distinct trips (e.g. from home to work, from work to lunch, etc.).

50. Yesterday, I used public transit (e.g. bus, subway, train, or streetcar)

Yes

No

51. Yesterday, I walked or used a bicycle Yes 
No

[ask only if individual indicates $>1$ in Q.47]

52. Yesterday, I used a personal vehicle (e.g. car, van, truck, SUV)

Yes

No

53. In the past 30 days, how often have you used each of the following car share or ride share services? [INSERT A TABLE WITH BUTTONS WHICH THE PARTICIPANTS CAN CLICK.]

\begin{tabular}{|c|c|c|c|c|c|c|c|}
\hline & $\begin{array}{l}\text { I never } \\
\text { do this. }\end{array}$ & $\begin{array}{l}\text { I do this, } \\
\text { but not in } \\
\text { the past } 30 \\
\text { days }\end{array}$ & $\begin{array}{l}1-3 \text { times } \\
\text { in the last } \\
30 \text { days }\end{array}$ & $\begin{array}{l}1 \text { day / } \\
\text { week }\end{array}$ & $\begin{array}{l}2-4 \\
\text { days / } \\
\text { week }\end{array}$ & $\begin{array}{l}5 \text { days } \\
\text { / week }\end{array}$ & $\begin{array}{l}6-7 \\
\text { days / } \\
\text { week }\end{array}$ \\
\hline $\begin{array}{l}\text { Used car2go car } \\
\text { share }\end{array}$ & & & & & & & \\
\hline $\begin{array}{l}\text { Used other car } \\
\text { share }\end{array}$ & & & & & & & \\
\hline $\begin{array}{l}\text { Used Uber ride } \\
\text { share }\end{array}$ & & & & & & & \\
\hline Used taxi & & & & & & & \\
\hline $\begin{array}{l}\text { Used a bike share } \\
\text { program (e.g. Bike } \\
\text { Share Toronto) }\end{array}$ & & & & & & & \\
\hline
\end{tabular}

[Note to Research Now: when hovering over "Uber" the participant should see the text: Uber refers to either Uber X or Uber Pool, but does not refer to Uber Eats."

[FOLLOWING QUESTION ONLY ASKED IF PARTICIPANT INDICATES THAT THEY HAVE USED UBER or TAXIS FROM ABOVE. If both Q64r3 and Q64r4 are 1, then Q64a should not be asked]

54. I primarily use Uber or taxis for the following trip types [MULTI-SELECT]:

Entertainment or recreation

Facilitating a passenger (e.g. giving somebody else a ride)

Shopping or errands

Work [paid employment] /School [university, college, or trade program] 
Other [ENABLE WRITE-IN].

[RN:FOLLOWING QUESTION ONLY ASKED IF PARTICIPANT INDICATES THAT THEY HAVE USED ONE OF THE FOUR CAR SHARE OPTIONS IN Q64 Columns 2-7. If Q58r1, Q64r1, and Q64r2 are all 1, then Q64b should not be asked.

55. I primarily use car share services for the following trip types [MULTI-SELECT]:

Entertainment or recreation

Facilitating a passenger (e.g. giving somebody else a ride)

Shopping or errands

Work [paid employment] /School [university, college, or trade program]

Other [ENABLE WRITE-IN].

\section{Travel Preferences and Choices}

\section{General Information and Views}

[INSTRUCTIONS]

In this section, we would like to ask about your views regarding your travel and housing

56. I have heard of the Google car before today

Yes

No

Unsure

57. I have heard of driverless cars before today

Yes

No

Unsure

\section{Automated Vehicle Opinions and Choices}

In this survey, we are interested in your preferences and opinions related to automated vehicles. Automated vehicles are cars which are equipped with technologies which reduce or eliminate the need for a human driver. 
Some automated cars can make driving easier or safer but would still require a human

driver. These vehicles include driver assistance technologies, such as:

automatic parallel parking,

vehicle communications to identify upcoming road conditions,

adaptive cruise control, and

automatic braking.

Other automated vehicles are driverless cars which can navigate the streets with no need for a human driver.

These vehicles currently look like conventional cars.

http://cogeng.cafe24.com/wp/wp-content/uploads/2016/01/google.jpg

[SHOW PICTURE]

Some driverless buses have also been designed and developed.

https://i.ytimg.com/vi/fEOT2sEps6Y/hqdefault.jpg

[SHOW PICTURE]

[next screen. Each of the following lines should be one click.]

Automated vehicles may improve the safety of travel.

Car collisions resulted in almost 2,000 fatalities and more than 10,000 serious injuries in Canada in 2013 (Transport Canada, 2013[2]).

Over $90 \%$ of car collisions can be attributed to human error, such as drunk or distracted driving

[3].

Google reported its first car collision caused by one of their driverless vehicles in February

2016. At that time Google's driverless vehicles had traveled more than 1.5 million kilometers with no human at the wheel[4].

[next screen]

Driverless and automated cars could play several possible roles in passenger travel in the future. [Each of the following possibilities should be prompted on the same screen but on separate clicks.]

Possibility A. Private ownership

Privately-owned driverless and automated cars may primarily be purchased by individuals and used as they wish.

Possibility B. Shared use

Shared driverless cars may primarily be used as fleets of roaming taxis which can be hailed or scheduled electronically. "Shared," means anybody can use them for a fare, not that you must share a ride with someone else.

Possibility C. Private and shared use

Both privately-owned and shared driverless cars could become common.

Possibility $D$. No future for driverless cars

Both privately-owned and shared driverless cars could play a very small or non-existent roles in the future of transportation. 
[next screen]

The next questions are designed to explore

a) your general interest in automated or driverless vehicles and

b) your interest based specifically on the shared or privately-held ownership models.

[QUESTIONS RESUME]

58. Which of the following potential benefits of driverless cars are most attractive to you? Select all that apply. [please make this multi-select]

Driverless cars are unattractive to me

Not needing to park (a driverless vehicle can drop me off and park itself).

Safety improvements

Being connected to data services while in the vehicle

Doing other things in the vehicle instead of actively driving

Supporting travel for adults with disabilities (e.g. vision, physical limitations)

Better traffic flow

More reliable travel

Fewer vehicle emissions

59. Would you be interested in using a driverless car on a regular basis?

Very interested

Somewhat interested

Unsure

Somewhat uninterested

Very uninterested

60. When would you consider purchasing a driverless car?

I would not purchase a driverless car

When $80 \%$ of my friends own one

When $50 \%$ of my friends own one

When $10 \%$ of my friends own one

I would buy one as soon as they are available

61. If you are purchasing a new vehicle, how much more would you be willing to pay for it to be available as a fully driverless car as opposed to a conventional car? [ASKED IF 


\section{EXISTING VEHICLE OWNERS IN Q46]}

62. I would not buy a driverless car

Less than $\$ 1000$

$\$ 1000-\$ 4999$

$\$ 5,000$ to $\$ 9,999$

$\$ 10,000$ to $\$ 14,999$

More than $\$ 15,000$

63. Vehicles with connected capabilities can communicate with each other or with traffic signals about routing or safety issues. Connected capabilities can be added to a conventional vehicle. Would you consider paying more for a vehicle with connected capabilities?
Yes
Maybe
No
Unsure

[Provide instructions.]

64. Some automated vehicles require a driver behind the wheel, but can fully control the vehicle in many (e.g. on freeways) but not all circumstances. When these vehicles need human drivers to take control, they provide an alert.

If you are purchasing a new vehicle, how much more would you be willing to pay for such a vehicle compared to a conventional vehicle? [ASKED OF EXISTING VEHICLE OWNERS]

I would not purchase an automated vehicle

It would need to be cheaper than a conventional vehicle

$\$ 1000$ or less

$\$ 1000$ to $\$ 4999$

$\$ 5,000$ to $\$ 9,999$

$\$ 10,000$ to $\$ 14,999$

More than $\$ 15,000$

Prospective Travel and Location Choices 


\section{[INSTRUCT THE SURVEY PARTICIPANTS]}

Please respond to the following scenarios based on the most likely changes to your own circumstances if you owned a driverless car.

65. Suppose using a driverless vehicle does not enable you to go faster but enables you to now use that travel time for other activities while traveling. Would you be likely to travel further to work (e.g. for a better job or less expensive housing)?

Yes

No

Unsure

66. Suppose using a driverless vehicle increases your commuting speed by $25 \%$ and also enables you to now use that time commuting for other activities while traveling. Would you be likely to travel further to work (e.g. for a better job or less expensive housing)? Yes

No

Unsure

Shared driverless cars may operate very similarly to Uber, which already operates in the Greater Toronto-Hamilton Area.

Uber has emerged as a technology-enabled mobility service which is like a taxi service, except it reduces the cost for users to find potential ride services to their destinations. Uber drivers are matched with customers using the Uber smartphone app.

Shared Driverless Vehicles

Imagine a future in which Uber-style shared (meaning, anybody can use them) driverless cars are available in the Greater Toronto-Hamilton Area. These cars would constantly be in circulation or be parked waiting for individual customers (just like taxis) and they would not have any human driver. The following questions ask how you might use such services and change how you travel.

\section{[NEXT SCREEN]}

The total cost of driving a conventional car typically ranges between $\$ 0.37$ and $\$ 0.88$ per kilometer, depending on what type of car you have, how expensive your fuel is, and how much you drive (Canadian Automobile Association, 2013[5]). This does not include the cost of parking. These costs can be divided into two types:

[After participant clicks next, both of these types appear on the same screen] Operating Costs (one-third of total costs): fuel and maintenance costs. You pay more of these for each trip you make. 
Ownership Costs (two-thirds of total costs): insurance, registration fees, taxes, etc. You have already paid for these costs simply by purchasing, registering, and insuring your vehicle. They do not change when you travel more or less.

\section{[FOLLOWING QUESTIONS ASKED OF ALL]}

67. If Uber-style shared driverless cars can pick you up and drive you anywhere in the Greater Toronto Area for a price of $\$ 0.50 / \mathrm{km}$, how often would you use this service for commuting or other trip purposes (not including accessing public transit)?

[if survey participant hovers over the parenthesis section here, the text should explain, "Here we are simply asking about door-to-door trips directly to your destination that could occur by driverless car, not (for example) trips in which you might take a driverless car to access a public transit station."]

Never

Less than once per month

Between one and 3 times a month

At least once a week

Daily

68. If Uber-style shared driverless cars can pick you up and drive you anywhere in the Greater Toronto Area for a price of $\$ 1 / \mathrm{km}$, how often would you use this service for commuting or other trip purposes (not including using accessing public transit)?

Never

Less than once per month

Between one and 3 times a month

At least once a week

Daily

[RN: If Q78== Row 1 (Never), skip Q79]

69. If Uber-style shared driverless cars can pick you up and drive you anywhere in the Greater Toronto Area for a price of $\$ 1.50 / \mathrm{km}$, how often would you use this service for commuting or other trip purposes (not including accessing public transit)?

Never

Less than once per month

Between one and 3 times a month

At least once a week

Daily 
[RN: If Q78== Row 1 (Never) or Q79== Row 1 (Never), skip Q80]

70. What is the highest price of using an Uber-style shared driverless car at which you would consider either selling one of your current vehicles or not replacing one as it ages?

I would not consider eliminating a current vehicle.

$\$ 0.25$ per kilometer

$\$ 0.50$ per kilometer

$\$ 1.00$ per kilometer

$\$ 1.50$ per kilometer

71. For what type of trips do you imagine using Uber-style shared driverless cars (independent of accessing public transit)? Select any that apply.

Entertainment or recreation

Facilitating a passenger (e.g. giving somebody else a ride)

Shopping or errands

School

Work

Other [ENABLE WRITE-IN].

I would not travel in an Uber-style shared driverless car

The following questions are about how you might use Uber-style shared driverless cars to access public transit.

72. If Uber-style shared driverless cars can pick you up and drive you anywhere in the Greater Toronto Area for a price of $\$ 0.50 / \mathbf{k m}$, how often would you use this service as a means of getting to/from a public transit station (for example, a GO or TTC station)?

Never

Less than once per month

Between one and 3 times a month

At least once a week

Daily

73. If Uber-style shared driverless cars can pick you up and drive you anywhere in the Greater Toronto Area for a price of $\$ 1 / \mathbf{k m}$, how often would you use this service as a means of getting to/from a public transit station (e.g. a GO or TTC station)?

Never

Less than once per month

Between one and 3 times a month

At least once a week 
Daily

[RN: If Q83== Row 1 (Never), skip Q84]

74. If Uber-style shared driverless cars can pick you up and drive you anywhere in the Greater Toronto Area for a price of $\$ 1.50 / \mathbf{k m}$, how often would you use this service as a means of getting to/from a public transit station (e.g. a GO or TTC station)?

Never

Less than once per month

Between one and 3 times a month

At least once a week

Daily

[RN: If Q83== Row 1 (Never) or Q85 == Row 1 (Never), skip Q85]

75. Would you be willing to share a ride in an Uber-style shared driverless car with another person?

Yes

No

Unsure

76. For what type of trips do you imagine using Uber-style shared driverless cars as a means of getting to/from a public transit station (e.g. a GO or TTC station)? Select any that apply. Entertainment or recreation

Facilitating a passenger (e.g. giving somebody else a ride)

Shopping or errands

Work [paid employment] /School [university, college, or trade program]

Other [ENABLE WRITE-IN].

I would not travel in an Uber-style shared driverless car

[RN: Do not ask Q77 if individual indicates "I would not buy a driverless ca]

77. If you owned a driverless car, how interested would you be in "leasing" that vehicle for a cost to others for individual trips when you do not need it?

Very interested

Somewhat interested

Uninterested 
78. If some of the GTA's neighborhoods had access to low-cost, near-immediate, and reliable Uber-style shared driverless vehicle services (like taxis), would such a service make a neighborhood more attractive to you?

Yes

No

Unsure

79. Would you be willing to use Uber-style shared driverless cars at a reduced price in exchange for sharing the vehicle for part of your trip with another customer?

Yes

Sometimes

No

Don't know.

80. How inexpensive would Uber-styled shared driverless cars need to be for you to exclusively commute using this mode (instead of how you currently commute to work/school)?
less than 25 cents per kilometer
less than 50 cents per kilometer
less than 75 cents per kilometer
less than $\$ 1.00$ per kilometer
less than $\$ 1.50$ per kilometer
Other
[ENABLE WRITE-IN]
I would never travel by driverless car

\section{Automated Vehicles and Public Policy}

81. Automated and driverless vehicles are likely to become more common in the future. How should governments respond?

Actively encourage the use of automated vehicles

Actively discourage the use of automated vehicles

Monitor the use of such vehicles and respond when necessary

Not be involved and let the market of consumers, driverless car manufacturers and service providers decide how and when these vehicles should be used

Unsure

82. Would you support investment to encourage, support, or regulate automated vehicles? 
Yes [then Q97]

No (skip Q97)

Unsure (skip then Q97) [this should now be "then"]

83. Should this investment be funded through additional taxes?

Yes

No

Unsure

84. How should automated and driverless vehicles impact public sector transportation spending in the Greater Toronto and Hamilton Area?

\begin{tabular}{|l|l|l|l|}
\hline Type of Investment & $\begin{array}{l}\text { Less } \\
\text { Investment }\end{array}$ & $\begin{array}{l}\text { More } \\
\text { Investment }\end{array}$ & $\begin{array}{l}\text { No } \\
\text { Change }\end{array}$ \\
\hline Public transit & & & \\
\hline Roads and Infrastructure & & & \\
\hline $\begin{array}{l}\text { System Operations and Demand } \\
\text { Management }\end{array}$ & & & \\
\hline
\end{tabular}

85. Do you expect governments to regulate how automated and driverless vehicles are used?

Yes

No

Unsure

86. Should governments become "innovators" and take the lead on using driverless cars?

Yes

No

Unsure

To exit the survey please click [HERE]. 
[final screen]

Thank you for having taken the time to complete this survey. Your time and input will play a critical role in supporting this study and informing policymaking.

The study team may conduct focus groups to further explore consumer attitudes towards automated vehicles. If you are interested in being considered for future focus groups on this topic, please send an email to driverlesscars@ryerson.ca .

[1] Question based on Transportation Tomorrow Survey (2011)

[2] https://www.tc.gc.ca/media/documents/roadsafety/cmvtcs2013_eng.pdf

[3] https://crashstats.nhtsa.dot.gov/Api/Public/ViewPublication/811059

[4] https://www.wired.com/2016/02/googles-self-driving-car-may-caused-first-crash/

[5]http://www.caa.ca/wp-content/uploads/2012/06/CAA_Driving_Cost_English_2013_web.pdf 


\section{References}

Alonso, W. (1964). Location and Land Use: Toward a General Theory of Land Rent. Cambridge, Massachusetts: Harvard University Press.

Anderson, J., Kalran, N., Stanley, K., Sorensen, P., Samaras, C., \& Oluwatola, O. (2014). Autonomous Vehicle Technology: A Guide for Policymakers. Santa Monica, CA: RAND.

Axsen, J., Mountain, D., \& Jaccard, M. (2009). Combining stated and revealed choice research to simulate the neighbor effect: The case of hybrid-electric vehicles. Resource and Energy Economics, Issue 3, p. 221-238.

Bansal, P., \& Kockelman, K. (2016). Forecasting Americans' Long-Term Adoption of Connected and Autonomous Vehicle Technologies. 95th Annual Meeting of the Transportation Research Board. Washington, DC: National Academies.

Bansal, P., Kockelman, K., \& Singh, A. (2016). Assessing Public Opinions of and Interest in New Vehicle Technologies: An Austin Perspective. 95th Annual Meeting of the Transportation Research Board. Washington, DC: National Academies.

Baum-Snow, N. (2007). Did Highways Cause Suburbanization? Journal of Urban Economics, 122(2), 775-805.

Chatman, D. G., \& Noland, R. B. (2013). Transit Service, Physical Agglomeration and Productivity in US Metropolitan Areas. Urban Studies, (Online First), 1-21.

Christaller, W. (1933). Die zentralen Orte in Suddeutschland. Jena: Gustav Fischer.

Davis, F. (1989). Perceived usefulness, perceived ease of use and user acceptance of information technology. MIS Quarterly 13 (3).

Daziano, R., Sarrias, M., \& Leard, B. (2016). Are consumers willing to pay to let cars drive for them? Analyzing response to Autonomous Vehicles. Washington: Resources for the Future. Retrieved from http://www.rff.org/files/document/file/RFF-DP-16-35.pdf

Deloitte. (2017). The Race to Autonomous Driving: Winning American Consumers' Trust . Retrieved from https://dupress.deloitte.com/dup-us-en/deloitte-review/issue-20/winningconsumer-trust-future-of-automotivetechnology.html?id=us:2el:3dc:dup3565:awa:dup:013117:dr20:fom:mfgblog

Diamond, D. (2009). The impact of government incentives for hybrid-electric vehicles: evidence from U.S. states. Energy Policy, 37 (3), 972-983. 
Fagnant, D. J., \& Kockelman, K. (2015). Preparing a nation for autonomous vehicles: opportunities, barriers, and policy recommendations. Transportation Research Part A, 77, $167-181$.

Fishbein, M., \& Azjen, I. (1975). Belief, Attitude, Intention and Behavior: An Introduction to Theory and Research. Addision-Wesley,.

Gatersleben, B. (2007). Affective and Symbolic Aspects of Car Use. In T. Garling, \& L. Steg, Threats from Car Traffic to the Quality of Urban Life (pp. 219 - 233).

Google. (2016). Retrieved from Google Self-Driving Car Project,.

Guerra, E. (2015). Planning for Cars That Drive Themselves: Metropolitan Planning Organizations, Regional Transportation Plans, and Autonomous Vehicles. Journal of Planning Education and Research, 1-15.

Hartig, T. (2007). Congruence and Conflict between Car Transportation and Psychological Restoration. In T. Garling, \& L. Steg, Threats from Car Traffic to the Quality of Urban Life. 103 - 122.

J.D Power. (2013). Owners Cite Fuel Economy-Related Technologies and In-Vehicle Smartphone Integration as Features They Are Interested in Purchasing in Their Next Vehicle,. Retrieved from http://autos.jdpower.com/press-releases/2013-us-automotive-emergingte

J.D Power. (2016). U.S Tech Choice Study. Retrieved from http://www.jdpower.com/pressreleases/2016-us-tech-choice-study

Krueger, R., Rashidi, T., \& Rose, J. (2016). Preferences for shared autonomous vehicles. Transportation Research Part C: Emerging Technologies. Retrieved from Krueger, R., Rashidi, T. H., \& Rose, J. M. (2016). Preferences for shared autonomous vehicles. Transportation Research Part C: Emerging Technologies, 69, 343-355. doi:10.1016/j.trc.2016.06.015

Kyriakidis, M., Happee, R., \& De Winter, J. (2015). Public opinion on automated driving: Results of an international questionnaire among 5,000 respondents. Transportation Research Part F: Traffic Psychology and Behaviour , 32, 127-140.

Lavieri, P., Garikapti, V., Bhat, C., Pendyala, R., Astroza, S., \& Dias, F. (2017). Modeling Individual Preferences for Ownership and Sharing of Autonomous Vehicle Technologies. Transportation Research Board.

Litman, T. (2017). Victoria Transport Institute . Retrieved from Autonomous Vehicle Implementation Predictions Implications for Transport Planning : http://www.vtpi.org/avip.pdf 
Muoio, D. (2016). These 19 companies are racing to put driverless cars on the road by 2020. Retrieved from The Guardian: http://www.businessinsider.com/companies-makingdriverless-cars-by-2020-2016-8/\#psa-groupe-the-second-largest-car-manufacturer-ineurope-is-aiming-to-have-fully-driverless-cars-ready-by-2020-17

Robertson, D., Meister, S., \& Vanlaar, W. (2016). Automated Vehicles: Driver Knowledge, Attitudes, and Practices. Traffic Injury Research Foundation.

Rogers, E. (1983). Diffusion of Innovations (3rd ed.). New York: Free Press of Glencoe., ISBN 9780029266502 .

Schoettle, B., \& Sivak, M. (2014). A Survey of Public Opinion about Autonomous Vehicles and Self-Driving Vehicles in the U.S., the U.K., and Australia. Ann Arbor, Michigan: University of Michigan Transportation Institute.

Shaheen, S., \& Cohen, A. (2012). Carsharing and Personal Vehicle Services: Worldwide Market Developments and Emerging Trends. International Journal of Sustainable Transportation,, No. 7, pp. 5-34.

Society of Automative Engineers. (2014). Society of Automative Engineers. Retrieved from http://www.sae.org/misc/pdfs/automated_driving.pdf

Statistics Canada . (2011). Retrieved from https://www12.statcan.gc.ca/censusrecensement/2011/as-sa/fogs-spg/Facts-cma-eng.cfm?LANG=Eng\&GK=CMA\&GC=537

Steg, L. (2005). Car use: lust and must. Instrumental, symbolic and affective motives for car use. Transp. Res. Part A: Policy Pract., 39, 125-145.

Transport Canada. (2014). Retrieved from Canadian Motor Vehicle Traffic Statistics: https://www.tc.gc.ca/media/documents/roadsafety/cmvtcs2013_eng.pdf

Von Thunen, J.-H. (1826). Von Thunen's Isolated State. (P. Hall, Ed., \& C. M. Wartenberg, Trans.) Oxford, United Kingdom: Pergamon Press.

Warner Jr., S. B. (1962). Streetcar Suburbs: The Process of Growth in Boston (1870-1900). Cambridge, MA: Harvard University Press.

Zmud, J., Sener, I., \& Wagner, J. (2016). Consumer Acceptance and Travel Behavior Impacts of Autonomous Vehicles . Texas A\&M Transportation Institute .

Zon, N., \& Ditta, S. (2016). Robot take the wheel: public policy for automated vehicles. Mowat Centre: Ontario's voice on public policy. Toronto: Mowat Centre. 